OPEN ACCESS

Edited by:

Urs Feller,

University of Bern, Switzerland

Reviewed by:

Morgan L. Ruelle,

Clark University, United States

Sylvie Lardon,

INRAE Clermont-Auvergne-Rhône-

Alpes, France

*Correspondence:

Cesare Zanasi

cesare.zanasi@unibo.it

Specialty section:

This article was submitted to Agroecology and Ecosystem Services, a section of the journal

Frontiers in Sustainable Food Systems

Received: 06 March 2020 Accepted: 17 September 2020 Published: 04 November 2020

Citation:

Zanasi C, Basile S, Paoletti F, Pugliese P and Rota C (2020) Design of a Monitoring Tool for Eco-Regions. Front. Sustain. Food Syst. 4:536392. doi: $10.3389 /$ fsufs.2020.536392

\section{Design of a Monitoring Tool for Eco-Regions}

\author{
Cesare Zanasi ${ }^{1 *}$, Salvatore Basile ${ }^{2}$, Flavio Paoletti ${ }^{3}$, Patrizia Pugliese ${ }^{4}$ and Cosimo Rota ${ }^{1}$ \\ ${ }^{1}$ Department of Agricultural and Food Sciences - DISTAL, University of Bologna, Bologna, Italy, ${ }^{2}$ International Network of \\ Eco-Regions (IN.N.E.R.), Salerno, Italy, ${ }^{3}$ CREA- Research Center for Food and Nutrition, Council for Agricultural Research \\ and Economics, Rome, Italy, ${ }^{4} \mathrm{ClHEAM}$ Bari - Center International de Hautes Etudes Agronomiques Méditerranéennes de \\ Bari, Bari, Italy
}

An Eco-Region (Biodistretto in Italian) is a rural area where different actors work together for the sustainable management of local resources, based on the principles and models of organic farming. Social, environmental, economic as well as ethical dimensions are involved. Eco-Regions are quickly growing in number in the EU and worldwide; different Eco-Regions types emerged, showing a variety of cultural, physical, socio-economic characteristics, and related policies and regulations. The Eco-Regions represent an innovative sustainable integrated rural development approach; their success can be supported by analyzing their basic features and their development dynamics. A balance between a strictly centralized and bureaucratic Eco-Regions management and a bottom-up non-regulated Eco-Regions proliferation should be provided to grant the development of community-based resilient initiatives. To this end a monitoring tool, based on the Porter's Diamond model, involving the local actors in analyzing the Eco-Regions structure and performances, could provide useful. Previous studies defined an Eco-Region monitoring tool, where different shortcomings characterized the analytical framework definition. The goal of the present paper is therefore to define an improved monitoring tool, more consistent to the Porter's Diamond model by reviewing the cluster related literature, focusing on the Porter's approach. The integrations resulting from the literature analysis contributed to a major increase in the indicators directly related to the original Porter's approach; new food security and sovereignty, as well as specifically designed sustainability indicators have also been added. By expanding the pool of indicators, the monitoring tool is more adaptive and able to support sustainable management of Eco-Regions in different contexts.

Keywords: monitoring tool, organic agriculture, Porter's Diamond, cluster, eco-regions, rural development

\section{INTRODUCTION}

The Eco-Regions represent a relatively recent innovative approach to the integrated territorial and rural development which operationalizes the recent rural policies, where organic farming plays a central role (Schermer, 2006; Stotten et al., 2017).

The International Network of Eco-Regions (IN.N.E.R), defines an Eco-Region as "An area where farmers, citizens, touristic operators, associations, and public actors established an alliance for the sustainable management of local resources based on the principles and model of organic farming in order to boost the economic and socio-cultural development of their territory" 
(Biodistretto.net, 2020). Eco-Region is also an attractive territory where the local community participate in developing and valorizing the Eco-Region natural and cultural resources. Organic agriculture, sustainable tourism, gastronomy also characterize the Eco-Regions contributing to their development (Basile, 2019).

The objectives of Eco-Regions involve, among others, the valorization of the Terroir, the promotion of food sovereignty and of social agriculture, the support of a sustainable organic agriculture development and the promotion of Mixed Farming. An Eco-Region is therefore an example of sustainable food system where the different objectives are clearly defined (Biodistretto.net). The Italian version of the term Eco-Regions, Bio-distretti (Organic farming districts), derives from its association to the Marshallian concept of industrial districts. A vast literature considered the industrial districts, starting from Marshall (2013) and further developed by various authors (Becattini, 1987, 1989; Sheppard, 2000). The term district in Italy is widely used also for agri-food districts and is sometimes overlapping the term cluster, which is applied to different economic sectors and branches. Adopting the term EcoRegion was therefore chosen by IN.N.E.R. following the idea of broadening the concept of organic and refer to a more ecological approach, and also to avoid the risk of possible confusion with industrial districts, mostly focused on manufacturing activities in its Marshallian version.

The Eco-Regions definition and goals are in line with the OECD Rural 3.0 paradigm (Tamara, 2018) and most policy orientations of the Cork 2.0 Declaration 2016 (European Conference on Rural Development, 2016).

Beside IN.N.E.R., different Eco-Regions definitions and policies, influenced by the regional and national contexts emerged in Italy (AIAB, 2017; Biodistretto.net, 2020), and other EU members (HealthyGrowth, 2017).

A global trend in the integrated rural areas sustainable development has recently emerged in the European Structural and Investment Funds $\left(\operatorname{ESIF}^{1}\right)$, within the framework of the UN Sustainable Development Goals (UN, 2019) and the UNESCO Biosphere reserves (WNBR, 2020). As far as the Global South is concerned, the FAO Community of Portuguese Language Countries (CPLP), the Food Security and Nutrition Strategy (Pinto, 2011), the UN Decade of Family Farming pillar 7 (Food Agriculture Organization, 2019) and the Agriclusters Development Strategy (Gálvaez, 2010) are all directly or indirectly referring to the importance of the Eco-Regions characteristics and objectives. This positively influenced the growth of Eco-Regions in the EU, where they are mostly concentrated, and in other important areas. In 2020, more than 40 Eco-Regions are operating in Italy. Other countries where the Eco-Regions have been implemented are Portugal, France, Austria, Switzerland and Spain. In other countries, such as Slovakia, Hungary, Germany, Tunisia, Morocco, the Eco-Regions are still in the formation stage. In 2019, projects

\footnotetext{
${ }^{1}$ ESIF Glossary - Regional Policy - European Commission. Available online at: https://ec.europa.eu/regional_policy/en/policy/what/glossary/e/esif (accessed February 8, 2020).
}

to establish new Eco-Regions were launched in Portuguesespeaking countries in the EU, Latin America and Africa. The global reach of Eco-Regions will expand thanks to a collaboration with different organic agriculture associations like the Asian Local Governments for Organic Agriculture (ALGOA) (more than 220 members in 16 countries and territories in Asia), IFOAM Organics International, IFOAM Asia, IFOAM EU Group, Baltic Foundation and OFSP (Organic Food System Program). The intention is to extend the cooperation from Asia and Europe to Africa, the Americas, Oceania and the Pacific Islands (Biodistretto.net, 2020).

Comparing the definition of clusters provided by Porter $(1998)^{2}$ with the Eco-Regions, the latter can be considered as a type of sustainable rural cluster.

According to Muro and Katz (2011) the competitive advantage of cluster-oriented initiatives [like the Eco-Regions] relates to their capacity to generate synergies among the local actors and to more effectively harmonize the development policies and related interventions to the local contexts.

The necessity to consider regional differences in the clusters development is also supported by Nolan et al. (2007). In particular Mondy et al. (2009) and Dorzhieva and Dugina (2015) suggest the necessity of adopting an integrated regional approach for an efficient and sustainable development of organic agriculture. A cluster analysis approach could therefore represent a more effective way to analyze the Eco-Regions structure, dynamics and performances. In an extensive review of the cluster policies economic impact Uyarra et al. (2012) emphasized the lack of "clear policy rationale... limited to some vague references to theory (e.g., Porter's model, systems of innovation)." Policy interventions should therefore be defined according to precise objectives and criteria to evaluate ex ante the programs. According to Feser and Luger (2003) and Uyarra et al. (2012) these evaluation criteria should be based on a flexible methodology in order to match the different clusters needs and support implementation of the policies chosen objectives.

Following these considerations, the design of a flexible context-related monitoring tool for the Eco-Regions should provide a contribution to their competitiveness and sustainable development. To this end a comprehensive framework, considering the different clusters location factors role in defining their structure and performances, is provided by the Porter's Diamond model (Porter, 1998, 2008). So far one study has explicitly designed a monitoring tool to assess the Eco-Regions performances (Pugliese et al., 2013), based on the Porter's Diamond model. The tool, tested in the Italian Eco-Region of Cilento, provided a clear and broad assessment of the different factors influencing the Eco-Region development. The main shortcomings of the study relate to the consistency of the analytical framework adopted to the Porter's approach mostly

\footnotetext{
"'Geographic concentrations of interconnected companies, specialized suppliers, service providers, firms in related industries, and associated institutions (for example, universities, standards agencies, and trade associations) in particular fields that compete but also cooperate. Critical masses of unusual competitive success in particular business areas, clusters are a striking feature of virtually every national, regional, state, and even metropolitan economy" (Porter, 1998).
} 
due to an incomplete literature review on: (i) the state of the art of the clusters analysis approaches, (ii) their empirical applications, (iii) a focus on the development of an effective Eco-Region monitoring tool design mainly as far as sustainability, food sovereignty, and security are concerned.

A second study on Mediterranean fishing communities (Malorgio et al., 2017) followed the same approach, only applied to a different context. Different improvements were made, consequent to the adoption of a more extended multistakeholders' approach in the different stages of the study implementation. This allowed for a definition of the analytical model and correspondent indicators, a questionnaire definition, data collection and results interpretation more appropriate to the local context. The study showed that the monitoring tool, specifically tailored for the Eco-Regions, can also contribute to the analysis of other similar contexts, where an integrated rural development, and in general a sustainable bottom up territorial development strategy, is implemented. Anyway, these works confirmed the common problem faced when trying and operationalize a complex theoretical construct as the Porter's Diamond model, that is the difficulty to translate it into clearly defined and consistent indicators (Boja, 2011). To improve the monitoring tool analytical framework consistency to the Porter's Diamond model, a more systematic approach to investigate the possible gaps in the previous monitoring tool design is needed. To this end a literature analysis focused on the link between the Eco-Regions objectives, structural characteristics, dynamics of development, and the Porter-based analytical approach, should be implemented. This will support a more effective monitoring tool design which can also be adapted to other contexts where a sustainable food system implementation is considered within a territorial perspective.

The goal of the paper is to support the development of food clusters in general and of Eco-Regions in particular, by designing an improved monitoring tool.

\section{MATERIALS AND METHODS}

An exploratory search is therefore conducted to identify papers related to the Porter approach, focused on their contribution to improve the design of an existing monitoring tool, assessing the clusters performances. The search deployed a combination of several key search terms to sample sources published in books, online articles and peer-reviewed journals. The search was applied to the titles, abstracts and keywords in online academic databases and library archives and Google Scholar. For the context of this research, terms related to the concepts of "Eco-Regions," "Organic Districts," "Biodistretti," "Cluster," "Porter Diamond," "Organic Agriculture," "Rural development," "Performance," "Classification," "Sustainability," "Food sovereignty," "Food safety," "Developing Countries," "Monitoring tool," "Stage of Development," "Market Orientation," "Tourism," and "Case Studies" were combined using the operators "AND" and "OR," in order to capture relevant references.

The papers resulting from the exploratory search underwent a further two-stage selection process. The exclusion criteria included at first the consistency of the title and abstract with the manuscript goals and scope. In a second stage the selection criteria involved the papers contents consistency with the manuscript goals and scope; the frequency of the paper's quotation and the date of issue. The selection supported the choice of relevant, updated seminal studies which were considered in the discussion.

In a first part the main theories and methods contributing to the definition of an Eco-Region analytical framework and the design of a monitoring tool have been reviewed, focusing on the contribution of the Porter's model to the analysis of clusters. The definition and identification of Rural Clusters was also considered to better understand how clusters are structured, can be identified and assessed. This static description is integrated by the analysis of the literature on the dynamics of clusters: how they start, develop and decline.

From the normative side the contribution of studies on the cluster policies will provide suggestions on how clusters can be managed in order to fulfill their goals.

Adjusting a monitoring tool design based on previous experiences and lessons learnt when analyzing, building and managing clusters, is also necessary. In particular the literature on Case studies of clusters analysis in general and more specifically on the assessment of the Eco-Regions performances, based on the Porter's Diamond model will be examined. Following the literature review results, a list of the requisites to be satisfied for an effective Eco-Regions monitoring tool design is defined and compared to the previous Eco-Regions monitoring tool (Pugliese et al., 2013). The list of suggestions resulting from the gap analysis will be integrated in an updated tool specifically tailored to the Eco-Regions monitoring needs, coherent to the Porter approach.

\section{RESULTS}

\section{The Literature Analysis The Porter's Cluster Theory}

The Porter's Diamond model describes different sources of location competitive advantage for clusters, derived from the previous studies on the Competitive Advantage of Nations (Porter, 1990). The sources of location competitive advantage have been grouped in a set of 6 determinants: (i) Context for firm Strategy and rivalry (ii) Factor (input) conditions; (iii) Related and supporting industries; (iv) Demand conditions; (v) History/Chance; (vi) Government.

A more detailed description of the analytical framework based on the Porter's Diamond model is reported in Table 1.

The original description of the different role of the Diamond determinants, and their interactions in influencing the clusters competitive advantage, is also integrated by other complementary analytical approaches (Porter, 1990).

Among them, social networks analysis, which considers the role of social networks in influencing the community cohesion and the flow of information.

Vertical and horizontal chains analysis is adopted to describe the clusters structure and the relation among actors.

Public and private policies and interventions on the development of clusters are also considered by Porter. The 
TABLE 1 | Porter Diamond model analytical framework.

\section{CONTEXT FOR FIRM STRATEGY} AND RIVALRY

Strategy (Strategic goals and management practices of Eco-Region stakeholders)

Climate for investments A local context that encourages appropriate forms of investment and sustained upgrading

Local policies affecting rivalry

Cooperation and Competition

\section{RELATED AND SUPPORTING INDUSTRIES}

provide an indirect support to the cluster core activities by activating complementarities (tourism - food agriculture) or supporting the products design, logistics, and after sales services

Presence of capable, locally based suppliers

Presence of competitive related industries

\section{DEMAND CONDITIONS}

Sophisticated and demanding local customers

Customers' needs that anticipate those elsewhere

Unusual local demand in specialized segments that can be served globally

\section{HISTORY}

Historical availability of pools of factors

Traditional unusual, sophisticated, or stringent local demand

Prior existence of industries

One or two innovative companies that stimulate the growth of many others

Cluster as product of an intersection between different clusters

Source: Porter (1998).

support provided by economic geography, as far as the definition and identification of clusters is concerned. The following parameters are defined by Porter (1990) (i) concentration (quantity and value), (ii) specialization toward outward oriented policy, both nationally or internationally, when size of supply far

Government role in Improvement of general micro-economic capacity of the economy

Formal Agreements and formal and informal collaborations private/public/civil society

\section{CHANCE}

Acts of entrepreneurship not related to location advantages

Acts partially related to locational antecedents

Chain of causality leading to company formation by creating advantageous factor or demand conditions exceeds local demand); (iii) specialization toward local markets (e.g., restaurant or touristic activities), and the presence of branches of external activities that serve the local market.

Different stages of clusters development are finally considered, including their decline. Different factors influencing the clusters development dynamics are described to this end.

Starting from the Diamond analytical framework (see Table 1) and the complementary analytical approaches above described, the following literature review will further analyze and integrate the Porter reference model. In particular contributions to the definition and identification of clusters, the clusters development stages and the role of public and private policies in the management of clusters are considered. A detailed and updated analysis of the factors more directly contributing to the EcoRegions monitoring tool design needs will be provided, in particular its scope and the choice of indicators.

\section{Contribution to the Porter's Diamond Clusters Analysis and to the Design of an Eco-Region Monitoring Tool \\ Clusters definition and identification}

Different studies provided indicators and conceptual frameworks to the clusters identification and classification with the aim of supporting effective development policies in different key regions like US (Nolan et al., 2007); EU (Stejskal, 2009; Center for Strategy and Competitiveness, 2020), China (Yu et al., 2013), and the Global South (Neven and Dröge, 2000).

In particular, within the Porter's analytical framework, these studies suggest the adoption of a mix of quantitative and qualitative indicators (Stejskal, 2009; Yu et al., 2013; see Box 1).
BOX 1 | Clusters classification methods.

Quantitative methods:

- Localization coefficients (LQ) Input-output analysis

- Shift-share analysis

- Gini coefficient of localization

- Ellison and Glaeser index of agglomeration

- Maurel-Sédillot index

Among qualitative methods we can count:

- Interviews with experts and management of the firms

- Researches (question-forms)

- Case studies

Source: Stejskal (2009).

These indicators are mostly oriented toward the definition of thresholds values for the clusters identification and selection related to the implementation of public policies. The application of quantitative indicators mostly oriented to assess the clusters core activity specialization lacks the capacity to identify more complex aspects like the presence of external economies of scale, economies of variety and scope, flexible specialization, and concentration. In particular when considering rural clusters and Eco-Regions, specific social characteristics related to the shared 
values of the local community are missing. The Italian legislation defining the rural districts (Decreto 18 Maggio, 2001) considers the cultural and territorial identity and the coherence of the cluster products with the local traditions and the natural and social context as requisites for their definition. The identification of the clusters is left to each local regional government, more adapt to assess the characteristics of the specific clusters contexts. Different studies and regulations address in particular the EcoRegions identification and classification: (Pancino et al., 2013; Pugliese et al., 2013; Legge 27 dicembre n. 205, 2017; Sturla et al., 2017). The Italian national and regional governments also support the creation and consolidation of Eco-Regions (Archivio Normativa Agricoltura Sociale ${ }^{3}$; Decreto 22 luglio, 2019).

A common trait linking these different definitions, mirroring the rural districts, is the multidimensional nature of the EcoRegions where environmental, social, and economic aspects are considered, and the definition of threshold quantitative indicators are missing.

An important feature of the Porter's approach is that the analysis should not only consider the identification of existing clusters but also the potential for some areas to become a cluster (Stejskal, 2009). This potential is described in terms of the capacity of the cluster to move the local (regional or national) economy and to make space for innovations. Innovation represents a "new rural paradigm" (Noronha Vaz and Gomes, 2013) gaining increasing relevance within the EU and international organizations. Clusters are therefore particularly suited to the most recent rural development policies orientation.

Supporting the clusters potential for development entails the necessity to provide indicators to assess their competitiveness; these indicators should be related to the clusters structure and socio-economic performances (Nolan et al., 2007) and based on the Porter's Diamond model. The same study also suggests different methods for data collection (secondary data, interviews, questionnaires) and the use of point scales in assessing the different dimensions of a cluster competitiveness. A last relevant suggestion is to integrate the interpretation of the results with experts' evaluations. The subjective nature of a cluster analysis, its context-dependent nature must therefore be considered when defining an Eco-Region monitoring tool. This view is also supported by Uyarra et al. (2012); they consider the necessity of flexible clusters monitoring and evaluation instruments to enable adaptation to the changing needs of the clusters.

The contribution of these studies to the design of an EcoRegion monitoring tool can be summarized as follows: the Porter Diamond model provides a theoretical framework for the clusters classification and competitive advantage analysis ( $\mathrm{Yu}$ et al., 2013); clusters classification and identification should not only relate to their selection (positive approach) but also support their development (normative approach); a monitoring tool is necessary to support the clusters definition and classification; the tool should be flexible enough to identify and classify the clusters and support their development, according to the local context

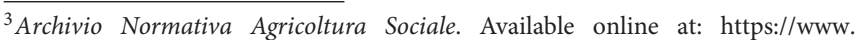
reterurale.it/flex/cm/pages/ServeBLOB.php/L/IT/IDPagina/15674 (accessed February 8, 2020).
}

needs; a mixed approach to the data collection and a scoring system should be adopted.

\section{Clusters dynamics (How they start, develop, and decline)}

Identification of Development Stages Understanding how clusters develop (Lee et al., 2016) is a necessary condition to assess the potential for development of the clusters and defining public and private policies for their development (Porter, 1998). Putting the results of a cluster analysis in a dynamic framework (the stage of development) provides valuable information on how the different characteristics of a cluster jointly contribute to its development stage (growth, maturity and decline). When considering the clusters development, Porter describes different stages (Porter, 1998) where at the beginning of a cluster formation local entrepreneurs are likely entrants followed by entrepreneurs external to the cluster, which either relocate or create subsidiaries at the cluster (lower risk is particularly attractive).

When new companies enter the cluster, innovation speeds up due to new businesses forming (e.g., by creating spin-offs from original larger companies). New innovative companies are then eventually acquired by established ones, if successful. As a consequence, clusters grow in breadth and depth (horizontally and vertically). The consequent intense competitive pressure selects the most efficient companies which can become more competitive than other companies outside the cluster. Eventually in a decline stage the investments and rate of innovation will slow down and productivity increases only through shrinking and outsourcing.

\section{Factors influencing the clusters development}

The presence of the following conditions influence the development of clusters (Porter, 1998): (i) the location overall favorable environment for new business formation, (ii) the intensity of local competition, (iii) the efficacy of formal and informal mechanisms for bringing cluster participants together.

When considering favorable location, flexible rules, lack of cartels, or other barriers to competition and to innovation, positively influence the intensity of competition, thus attracting investments. When information about opportunities (gaps in products, services, or suppliers to fill) is more accessible, barriers to competition are lower in clusters. Other favorable location factors are the presence of readily available assets at the cluster location (skills, inputs, and staff) and a more accessible credit through local financial institutions, possibly requiring lower risks premiums. From the demand side clusters can provide and easier market access when a significant local market is present.

As far as the relationship among actors in a cluster is concerned, the existence of easier relations with members of a local community (trust, commitment etc.) induce higher collaboration. Collaboration promotes cohesion, frequent exchange of knowledge and innovation (bridging) and a further lowering of the barriers to entry, due to a reduction in the perceived risk to start an activity.

Collaboration can also enhance cluster productivity, through better exploiting complementary skills and joint actions creating external economies of scale. 
Clusters development is encouraged by social interactions and local governance able to include small scale and medium sized producers (Ramirez et al., 2018).

Starting a cluster adopting a bottom up approach where "individuals, companies and institutions take responsibility" (Porter, 2008) can therefore provide a more effective development. This assumption is confirmed in a study on the role of bottom-up initiatives in the participation of actors in clusters (Ramirez et al., 2018).

Other authors state that clusters cannot be created from scratch by top down government-backed initiatives (Muro and Katz, 2011). Another study supports this view by considering that creating clusters without pre-existing locative advantages almost invariably leads to failures (Porter and Ketels, 2009).

This also applies to the agri-food sector, where a study analyzing the establishment of a network of different institutions, related to organic farming, showed the high risk of failure in creating shared vision and actions consequent to a top down strategy (Crivits et al., 2018).

Relations between clusters are also relevant. Intersections between different neighboring clusters can influence their development by originating new clusters, attracting investments and new human resources (technicians managers scientists etc.) from other areas. These studies suggest that the EcoRegions should increase their coordinated efforts, when needed, but should also encourage a differentiated and vital array of ideas, coming from independent, motivated, sometimes competing, Eco-Regions.

In general, the contributions to the study of the factors influencing the development of clusters confirm the effectiveness of the Porter's Diamond analytical framework as a reference for an Eco-Regions monitoring tool design, in particular as far as the choice of indicators is concerned.

\section{Cluster public and private policies influence on clusters development}

According to Porter and Ketels (2009) government policies can be better designed and be more effective if cluster participants are organized to work with government. This includes trade associations, entrepreneurs' networks, standard setting agencies, quality centers, technology networks, and many others. According to a study on Clusters and Public Policy from Ketels (2013) public policy and public investments can be more efficiently organized within the favorable framework provided by a clusters. This will support the clusters economic development by attracting businesses from outside, promoting export, protecting natural resources and the sustainable management of the environment.

The same author also provides different suggestions on how to effectively manage the interaction between clusters development and policies. First of all, cluster policies should be aligned with the specific-conditions in the location and with the nature of the existing clusters. Best practices should be shared in cluster initiative management and clusters development should be integrated into a broader strategy of upgrading regional competitiveness.
A similar set of implications for effective policies are listed in a study on the clusters policies (Andersson et al., 2004) which adds some interesting remarks related to the necessity to support policies by assessing the clusters viability and strength.

Last but not least Porter suggests a list of actions governments should take in order to upgrade the Clusters (Porter, 1998) The main pillars of the Governments actions should be the achievement of macroeconomic and political stability and the improvement of the general microeconomic capacity of the economy; competition should be regulated and incentivized to encourage the development of already existing and emerging clusters.

More detailed suggestions on the government role in clusters development are listed in Figure 1A.

Indications on private businesses actions to support the Eco-Regions development are also provided (Porter, 1998; see Figure 1B). The main areas of intervention relate to supporting education and research, managerial skills and a coordinated effort with local government. Similar actions are suggested with reference to trade associations and collective bodies. Specific roles played by these actors involve the possibility to perform lobbying activities and in general to generate external economies of scale by supporting a joint access to inputs and the final products and services markets (Porter, 1998). An effective involvement of public, private and civil society organizations in the clusters development policies should follow the circular subsidiarity principle (Bruni and Zamagni, 2016). According to this principle the different actors define flexible relations in order to compensate each other weaknesses according to the task that needs to be implemented and to their financial resources, skills, knowledge, and political influence.

These aspects are particularly relevant to the EcoRegions, in particular considering their relatively recent history, characterized by an acceleration in growth and internationalization, where many independent approaches and regulations are continuously emerging. In this pioneering stage the importance of a balanced interaction between formal and informal organizational norms is also of paramount importance following the suggestions of Agrawal et al. (2013) when analyzing the sustainable resource use in rural communities. An approach to the Eco-Regions analysis and regulation where the specific characteristics of each Eco-Regions should be valorized, avoiding a strict formal, and standardized definition of their characteristics and objectives, should therefore be followed.

The design of a monitoring tool, the results interpretation, and mostly the support to the definition of public and private policies should be consistent with these general suggestions.

\section{Contribution of Clusters Case Studies, Based Upon the Porter Diamond Model, to the Design of a Monitoring Tool \\ Clusters in general}

The Porter's Diamond model has been adopted in different extensive studies on clusters; among them the Cluster MetaStudy (https://www.isc.hbs.edu/Pages/default.aspx, 2019) from the Institute for Strategy and Competitiveness at Harvard Business School, and the two Cluster Initiative Greenbooks 


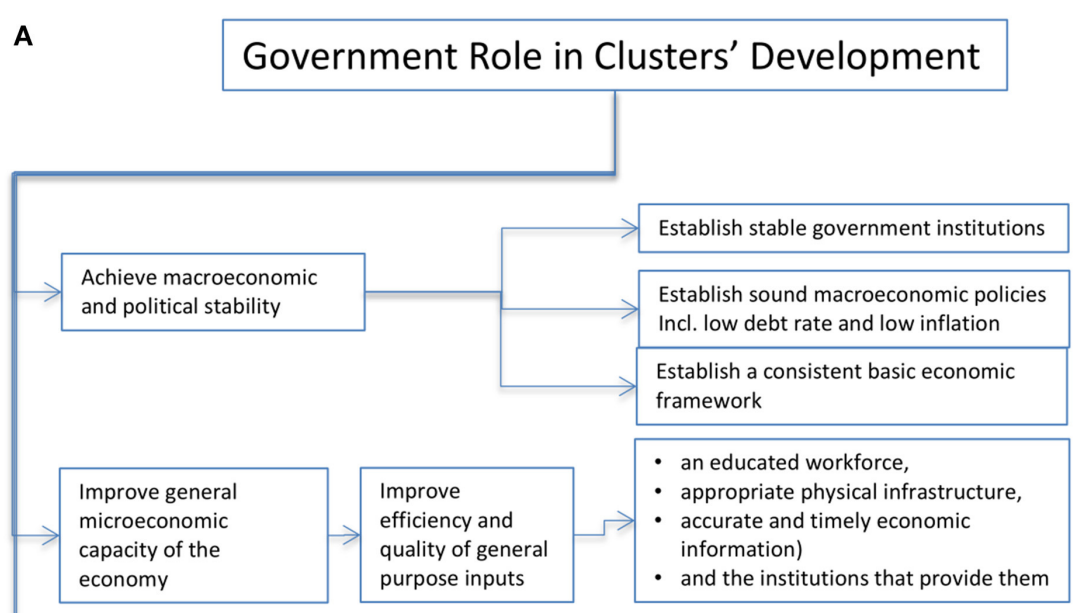

Establish the overall
microeconomic rules and
incentives governing
competition that will encourage
productivity growth.
productivity growth.

- a competition policy enhancing rivalry
- a tax system and intellectual property laws encouraging investment
- a fair and efficient legal system,
- laws providing consumer recourse
performance governance rules holding managers accountable for
- an efficient regulatory process promoting innovation rather than
freezing the status quo

facilitating cluster development and upgrading of all

clusters, not choose among them.
The process must encompass the general conditions affecting all industries as well as the upgrading of clusters. The clusters' success should be determined by market forces, however, not by government decisions

Ideally, such a process should occur not only at the national level but at the state and city level as well. It should concern not lobbies but all the stakeholders in a cluster

B

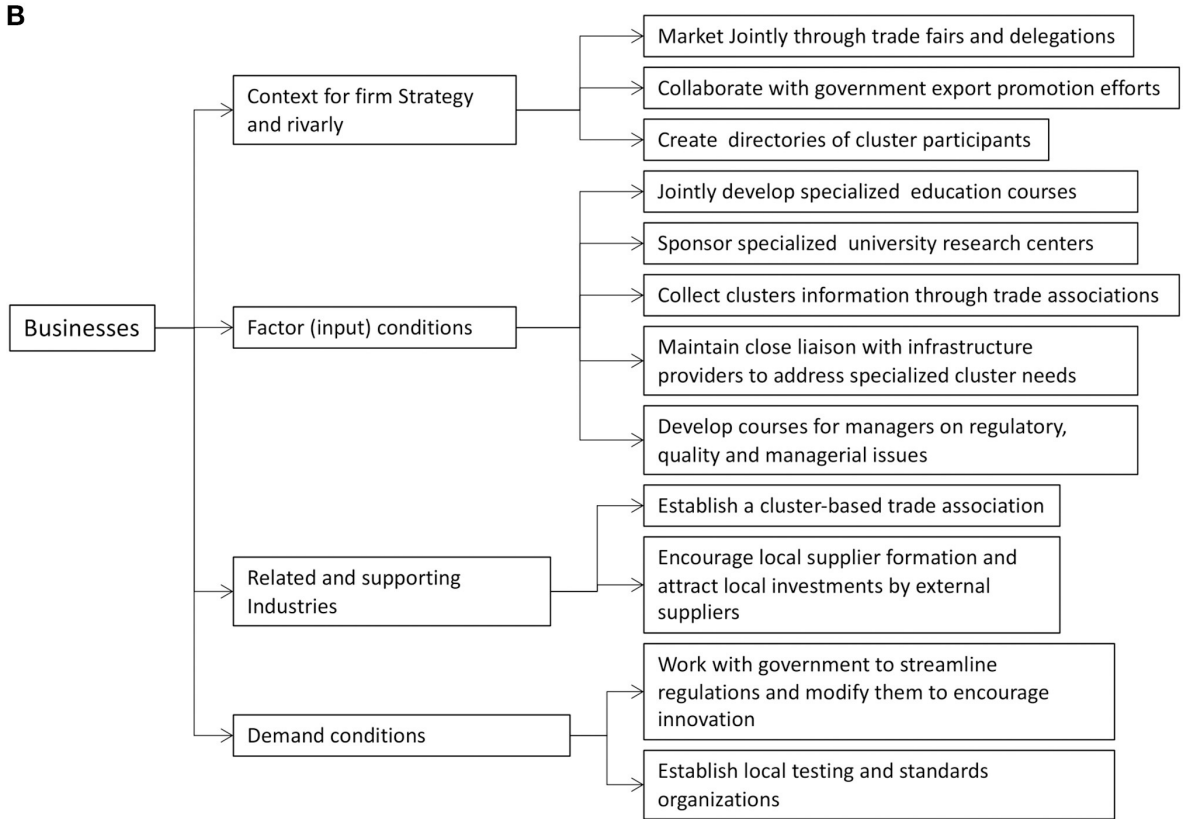

FIGURE 1 | (A) Government role in Clusters' Development. (B) Corporate role in Clusters' Development. Source: Porter (1998). 
(Solvell et al., 2003; Lindqvist et al., 2013). Covering a large number of clusters initiatives at a global level these studies provide a description of different clusters structure and types, their evolution and the factors influencing their performances. The results provide important suggestions as far as a cluster monitoring tool design, results interpretation and application are concerned. First of all, the clusters diversity in terms of objectives, location, role, and size of the stakeholders, was confirmed; moreover, the clusters continuous evolution and their strong links to the context emerged. As a consequence, the difficulty to provide a comparison among different clusters performances resulted, since the same indicators can have different relevance in different contexts.

Another important contribution to a monitoring tool design, coming from the first Cluster Initiative Greenbook (Solvell et al., 2003), is the definition of a four stage lifecycle of clusters (development) based on the degree of institutionalization and the objectives of the initiative. The following stages are reported: (i) antecedence related to the pre-conditions contributing to the birth of a -cluster; (ii) formation: initiatives launched by industries, governments or academia, catalyzing the formation of a cluster; (iii) launch of cluster initiatives; and (iv) formal cluster-based institution for collaboration.

Two relevant contributions to the cluster performance analysis come from the Greenbook 2.0 (Lindqvist et al., 2013). The first one relates to the scoring of the performance, where Likert scales from 1 to 7 were adopted; the second concerns the definition of an ideal model of fully developed cluster where the different actors perfectly collaborate, providing a benchmark for the assessment of the cluster development stage.

\section{Rural clusters}

A specific analytical framework for the study of rural clusters is defined by Porter in its study on Competitiveness in Rural U.S Regions (Porter et al., 2004). Two main contributions to a monitoring tool design can be found in this study. The first one regards the definition of three types of market orientation for the cluster industries. Local industries providing goods and services mostly to the local market; the Resource dependent industries: relying upon local resources and compete both at the local and national and international level; traded industries which are not dependent on local resources. The influence of the clusters market orientation on the competitiveness of rural clusters emerged; according to the author the competitiveness of rural clusters depends on how different combinations of these type of industries match the characteristics of the different contexts. The second relevant contribution, integrating the Greenbook 2.0 description of ideal clusters, comes from this study. The focus is not, in this case, on the level of collaboration between actors, but on the structural development of the cluster, in terms of specialization and range of locally available resources and activities, as depicted in the Porter's Diamond (Porter et al., 2004).

\section{Clusters in developing countries}

A framework for the analysis of agri-food clusters in developing countries have been proposed, where the Porter's Diamond model is compared to the Collective Efficiency and Flexible Specialization, the traditional frameworks adopted in the analysis of clusters in developing countries (Neven and Dröge, 2000; Gálvaez, 2010). The studies support the adoption of the Porter's Diamond model also in the least developed countries, where conditions for the development of clusters seem not to be significantly present (Neven and Dröge, 2000); the same authors consider the importance of assessing the potential for cluster growth (hidden resources) in spite of significant frictions constraining their development (Neven and Dröge, 2000). A mixed public private intervention top-down is suggested by a study from FAO (Gálvaez, 2010) in order to reduce these frictions. This broadens the scope of the Porter's Diamond application to areas where clusters are not yet present, like those in the Global South. The studies on clusters analysis applied to developing countries provide a further contribution to their classification according to the stage of development based on the Collective Efficiency key constructs: external economies and joint actions. Among them the McCormik classification (McCormick, 1999), based upon a study of six African clusters, defines the following types of clusters: (i) groundwork clusters in which precondition exist paving the way for the cluster to emerge; (ii) industrializing clusters where the process of specialization, differentiation and innovation begins; and (iii) complex industrial clusters where the clusters show three important characteristics in common: firms of different sizes; the many small firms use simple technology and tend to depend on large firms for their markets; and perhaps most important, the market reach of the clusters expands to reach a national or global dimension (McCormick, 1999).

\section{Rural tourism clusters}

The direct influence of other sectors in the rural development is stressed in the Porter's Diamond approach (Porter et al., 2004) and in particular how tourism and other non-agricultural aspects like recreation and retirement contributed to the rural areas growth.

The interplay between food, tourism, culture, and landscape in clusters is also analyzed in different other studies based on the Porters' approach exploring the link between agriculture and tourism (Babalola et al., 2011; Lee et al., 2016). An interesting consideration on the interplay between public policies and rural areas can be found in a study on rural tourism clusters (Székely, 2014). The author underlines the different risks a complex system as a rural tourism cluster can be subject to; among them the risk of dependence on public funding, the high risk of conflicts between different stakeholders or the possible neglect of environmental sustainability strategies to increase a short-term profit perspective. Not all rural areas are therefore appropriate to develop cluster initiatives in tourism, depending on their economic, social and cultural characteristics.

\section{Empirical Applications of Porter's Approach to Rural Clusters and Eco-Regions \\ Rural clusters cases}

A series of studies on microeconomics and competitiveness, from the Institute for Strategy and Competitiveness founded in 
Harvard by Michael Porter (Harvard Business School, 2019), applied the Diamond model to the Agri-Food sector. The country economic and social performances were first described, and a competitive analysis followed, based on the Diamond model determinants. A detailed description of the clusters context, performance, and competitiveness and a final set of recommendations, was also provided (Porter et al., 2013). A description of the agrifood value chain and of the clusters structure in the Malaysian palm oil and Egyptian textile clusters was included in two studies (Belai and Boakye, 2011; Abdallah et al., 2012). The importance of communication, networks, and tacit knowledge for the clusters success is stressed in a study on the dynamics of the Norwegian maritime industry (Gunther Egi, 2014). In these relative short reports, the analytical as well as normative part (strategies suggestions) are based upon a descriptive approach where the evaluation of the different dimensions of competitiveness is supported by quantitative and qualitative secondary data (statistics and other official documentations and studies). The adoption of metrics for the clusters performance assessment has been proposed in a study suggesting that it can help improving the clusters management and competitivity (Carpinetti et al., 2008). The necessity to adapt the measurement system to the resources available and the informal, emergent, strategy definition process of SMEs, characterizing the Clusters, is also stressed by Hudson et al. (2001).

An empirical application of a performance assessment to clusters, based on the Porter's Diamond model, has been developed in different studies, adopting a scoring system based on Likert scales.

Among them a study (Bakan and Dogan, 2012) developed a new model to test the impact of the Diamond model variables on the [clusters] competitiveness. A list of structured indicators, measured through a Likert scale, have been defined; semi-structured and unstructured questions, involving the participation of stakeholders have also been collected (Bakan and Dogan, 2012). One important feature of the study is the application of different models of simple regression analysis to assess the influence of the different Porter's Diamond related indicators on the performance of the clusters.

The use of different simple regression models which consider only one explanatory variable, confirms the difficulty of defining a more complex statistical model describing a cluster competitive performance; the presence of multicollinearity could be the reason.

\section{Eco-Regions}

Recent studies and government regulations, directly linked to the Eco-Regions, contributed to the integration of the monitoring tool analytical framework as defined in the study from Pugliese et al. (2013).

These studies suggestions are in line with most of the literature on clusters analysis, confirming the Eco-Regions as a type of rural cluster. Considering the centrality of organic agriculture in the Eco-Regions, some topics, like the necessity to introduce socioeconomic and environmental indicators in the analysis (Pugliese et al., 2015) were emphasized. Other interesting contribution to the design of an Eco-Region monitoring tool emerged: the opportunity to use quantitative indicators for qualifying the Eco-Regions (Pugliese et al., 2015), the role of innovation, diversification and integration in rural development (Sturla et al., 2017), the importance of a strong local identity in defining an Eco-Region (Legge 27 dicembre n. 205, 2017), and the importance of a stakeholders network and a supply chain analysis (Stotten et al., 2017).

\section{Integrating Sustainability Food Safety, Security, and Sovereignty in an Eco-Region Monitoring Tool Based on the Porter's Diamond Approach}

As previously stated, Eco-Regions are clusters of activities strongly related to organic agriculture, defining a sustainable food system. Consequently, sustainability should be included in the analytical framework and in the monitoring tool design.

Environmental and in general sustainability issues applied to agri-food clusters are not specifically addressed by the Porter's Diamond approach. The importance of direct structural changes oriented toward a more sustainable development of food systems and rural areas is stressed by Knickel et al. (2018); this will contribute to reduce the social, environmental and economic imbalances. Different studies can contribute to more explicitly include sustainability indicators in the Porter's analytical framework and in the Eco-Regions monitoring tool.

In a study on the potential of Industrial Ecology in agrifood clusters (Simboli et al., 2015) the importance of providing solutions by involving and coordinating different companies and the support of local stakeholders is stressed. Another paper links rural systems, in particular Eco-Regions, to sustainability (Lamine, 2015). The author suggests the necessity to consider the Eco-Regions contribution to the development of alternative and more resilient pathways since they involve "diverse relations between agriculture, food and the environment."

Food safety, security, diversity, and sovereignty should also be assessed from a social economic, and environmental sustainability perspective.

Food sovereignty in particular is relevant to the Eco-Regions since it involves not only food security but also considers the role of the local communities in controlling the way food is produced and how food production should be in harmony with the local communities culture and in general their eco-system (Gordillo, 2013).

The inclusion of these topics in an analytical framework for the design of an Eco-Region monitoring tool is not relevant only because they contribute to assess the Eco-Regions compliance to their vision and funding values; as far as the Porter's Diamond model is concerned, sustainable food related indicators also represent location factors positively affecting the Eco-Region development; food sustainability represents in fact one of the main features characterizing their activity, creating a favorable context for the demand of product and services (Biodistretto.net, 2020). Different analytical frameworks have been defined to assess the dimensions of food production sustainability; one important source is the Sustainability Assessment of Food and Agriculture Systems framework (SAFA), developed by FAO [Food and Agriculture Organization (FAO), 2013], where a 
very large number of indicators directly or indirectly connected to food safety, security and sovereignty is considered. The four pillars of nutrition security (African Union Commission, 2018) provide another interesting contribution to improve the food sustainability analysis; the concept of, and the variables influencing, food availability, accessibility, use and stable supply, risk reduction, environmental sustainability, are defined. Two more studies seem particularly suited to support the definition of food sustainability indicators to be included in the monitoring tool (Remans et al., 2014; Gustafson et al., 2016). Different indicators of food security and diversity are collected from various sources; a social economic and environmental sustainability perspective on food safety, sovereignty, and security is also considered. Seven food system indicators of sustainable nutrition security have been extracted, measuring food nutrient adequacy, the ecosystem stability, food affordability and availability, socio-cultural wellbeing, resilience, food safety, and waste and loss reduction (see Supplementary Table 1).

\section{Integrations to the Existing Eco-Regions Monitoring Tool}

Based on the literature review, an effective Eco-Region monitoring tool design (see Supplementary Table 2) should be based on an analytical framework consistent to the Porter's model construct and provide a knowledge base supporting, and not substituting, the Eco-Regions stakeholders in their decisions.

In particular the economic/environmental/social locative advantage performances of the Eco-Regions, their development stage, the potential market orientation and the compliance of the Eco-Regions to a commonly agreed set of basic characteristics, should be included as a support to private and public development strategies definition.

An Eco-Region monitoring tool should also consider the centrality of organic agriculture and therefore involve sustainability more clearly; it should also be flexible enough to adapt to different Eco-Regions contexts and objectives and recognize the extent of the bottom-up approach contribution to the development of the Eco-Regions and in general of the role of local communities. Considering the importance of knowledge/best practice exchange among the different Eco-Regions, the monitoring tool should be based on a commonly agreed set of technical terms and pool indicators. The indicators should provide fine grained quantitative and qualitative information about the institutional or resource deficiencies of the local clusters, essential to target and bound proposed interventions (Muro and Katz, 2011).

Consequently, the choice of indicators, the data collection, and results interpretation should be implemented adopting a multistakeholder's approach where a Monitoring Tool Implementation Team (MTIT), designing and managing the monitoring tool and a Local Tool Implementation Team (LTIT) including representatives of the Eco-Regions, should be involved.

The Porter's approach allows for balancing the inherent complexity of a model describing a multidimensional rural system with its usability, supporting a multi-stakeholders' dialogue. The Eco-Regions stakeholders capabilities are in fact variable; both the analytical framework logic and the indicators adopted should be understandable to a non-specialized user; this will positively affect the jointly performed data collection and the results interpretation stages.

When comparing the previous monitoring tool (Pugliese et al., 2013) to the requirements listed in Supplementary Table 2, the results show that some important gaps still need to be filled. In particular, the inclusion of new indicators referring to social, environmental, and economic sustainability (and the related food security, safety, and sovereignty) and tourism, should be added, to improve the consistency and better match the scope of the analytical framework with the Porter's Diamond approach and with the Eco-Regions information requirements.

The description of the Eco-Region context (macro and microeconomics factors attracting investments) was also missing. The role of Demand, Government, History, and Chance should also be more clearly designed by adding new and/or better tailored indicators. These aspects will be considered in the design of the monitoring tool.

\section{The Eco-Region Monitoring Tool Design General Analytical Framework}

The structure and content of a new analytical framework and monitoring tool design are based on the contributions coming from the studies on the Italian Eco-Regions and Mediterranean coastal communities (Pugliese et al., 2013; Malorgio et al., 2017).

The definition of the analytical framework (see Figure 2) answers questions related to the steps to be performed when applying the Eco-Region monitoring tool. First of all, the present characteristics of the Eco-Region are monitored, in particular the Eco-Region locative competitive advantages and its context analysis (modules 1 and 2). The Eco-Region stage of development (module 4) and its compliance to the characteristics defining an Eco-Region are also assessed (module 3), together with the definition of its potential (more efficient) market orientation (module 5).

On the base of this first monitoring of the Eco-Region, a support to the design of the Eco-Region development strategy is provided.

In turn, the results of the strategy implementation will be monitored and experiences (errors, best practices) can be shared with other Eco-Regions.

To balance the usefulness and usability of the monitoring tool it is suggested that the choice of number and type of indicators be consistent with the information availability, the time, human and financial resources available, and, most of all, with the overall Eco-Region context. A sustainable number of indicators can provide a first set of information showing the Eco-Regions critical areas and suggesting where to focus a more detailed analysis. A relatively simple cause and effect analysis (5 whys) (Serrat, 2017) could be useful to this end. Since each Eco-Region is different from the others the local Eco-Region actors and the Monitoring Tool Implementation Team (MTIT) should jointly adapt the tool structure (choice of indicators), the questionnaire definition, the data collection procedures, the performances scores and the results interpretation, to the local context. An activity action map (see Figure 6) has been added to detail the different steps of the monitoring tool implementation. 


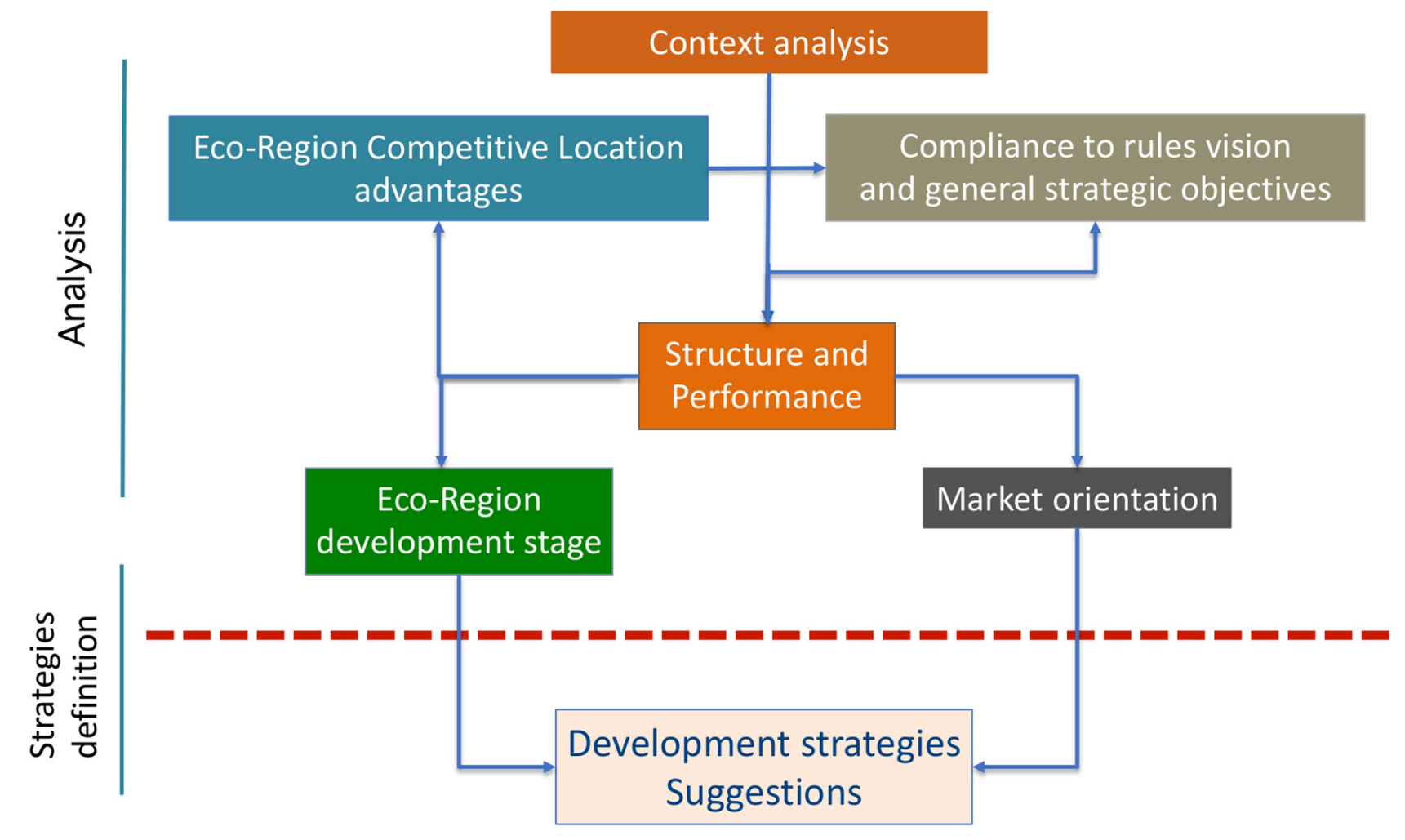

FIGURE 2 | Eco-Regions' Monitoring tool modules. Adapted from Pugliese et al. (2013) with permission from CIHEAM Bari.

\section{Module 1 Eco-Region Structure and Performance Analysis}

Aim and analytical framework

The aim of this module is to assess the relevance of the location factors contributing to the Eco-Region competitiveness, according to the Porter's model. This module provides a multidimensional perspective on the Eco-Region complex structure and dynamics and also represents the core of the entire monitoring tool; the indicators included in the analysis provide in fact further specific information necessary to the other models assessing the development stage of a cluster, market orientation and compliance to the funding principles of Eco-Regions.

The analytical framework (see Supplementary Tables 3A-F), consistent with the Porter Diamond model (Porter, 1998) is divided in Determinants, Categories and indicators. For each indicator the users should define one or more questions; a correspondent integrative comment motivating the score, or providing additional information can be added, to support the data interpretation. While the choice of Determinants and Categories mirrors exactly the Porter's model (see Table 1), the indicators suggested have been adapted to the Eco-Regions possible different information needs, resulting from the literature analysis and the previous design of the monitoring tool. A pool of indicators is consequently listed in the questionnaire, italics is used for the indicators of the previous monitoring tool. Each EcoRegions can choose, modify or add other indicators according to their relevance to the context both in space (differences among Eco-Regions) and in time (changes in the same EcoRegion when monitoring their performances over time). The inclusion or modification of the indicators should be consistent to the Diamond model theoretical approach. The questions formulation should be jointly discussed with the Local Tool Implementation Team (LTIT) conducting the interviews, and the local respondents.

\section{Questionnaire validation and data collection}

The questionnaire data should be collected by interviewing the most representative stakeholders within the different communities, covering a wide range of perspectives and interests related to the Eco-Region development.

Before starting the data collection, the Local Tool Implementation Team (LTIT) should be trained by providing written and audio guidelines to the project overall structure and strategy and a detailed explanation of the questionnaire and context analysis structure and contents.

An interactive session will follow to align the knowledge of the different respondents.

A meeting among the different local stakeholders will then be held where the different issues emerged during the previous stages will be discussed: the questionnaire and context analysis contents, structure and goals will be debated as well as the possible adjustments to the local contexts. A pilot test will be performed to test if the previous conditions are satisfied. 


\section{Performance score calculation based on the porter's diamond model}

The data collected should be measured based on a Likert scale from 1 to 5 .

The scores vary from 1 to 5 in ascending order of contribution to Eco-Region performance ( 1 most negative 5 most positive $)^{4}$. An initial score for each indicator is attributed by the MTIT on the base of the average score provided, compared, when possible, with the findings of the Context analysis; in case of answers showing opposite signs (e.g., 1-2/ negative vs. 4-5/ positive) the interviewers will be contacted and asked to provide their evaluation on the reasons for contrasting scores and, eventually, the opinions of local experts will be collected to confirm the choice of the indicators score. A final decision on the divergent indicators scores will be taken by the team responsible for the report implementation on the base of the previous steps. Each score will be briefly motivated.

The different indicators score will be progressively aggregated according to the different classes and determinants defined in the analytical framework. The aggregated score will result from an average of the different values. A weighted average calculation, similar to the subjective multicriteria weight assignment (Odu, 2019), could be also calculated to account for the most influential performance indicators, given the different EcoRegions contexts. The weighted average should therefore result from a consultation with local stakeholders representing different perspectives and interests. The same scoring and aggregation criteria should be applied to the definition of the compliance to the basic objectives and values of the Eco-Regions, the development stage and the potential market orientation.

A final feedback on the data interpretation and development strategies suggested by the (MTIT), will be provided by the LTIT, which collected the data in the different Eco-Regions.

\section{Module 2 Eco-Regions Context Analysis}

The aim of the Context analysis is to provide an integration to the Structure and Performance analysis results. An example of data which, given the previous analysis experience (Pugliese et al., 2013), can be relatively easy to collect in a typical Eco-Region is reported in Table 2. They should be intended as a reference framework describing relevant data categories necessary for a Context analysis of an Eco-Region.

The context analysis integrates the Diamond model with two important contributions: the stakeholders map and the supply chain description.

The stakeholders map considers the structure of the network, the different roles of the stakeholders, and their relations.

\footnotetext{
${ }^{4}$ Even if less reliable than objective data, the adoption of a subjective Likert scale for the Diamond model performance analysis has been considered for two main reasons: first it allows to aggregate the Eco-Regions performance scores and compare the different performance indicators; second it is a relatively simple way of collecting information on the characteristics of the Eco-Regions, which are often difficult to measure adopting statistical sources; the Eco-Regions boundaries do not always overlap the administrative regions and/or the level of their spatial disaggregation could be too detailed to easily access statistics or other secondary data.
}

TABLE 2 | Eco-Regions Context analysis suggested indicators.

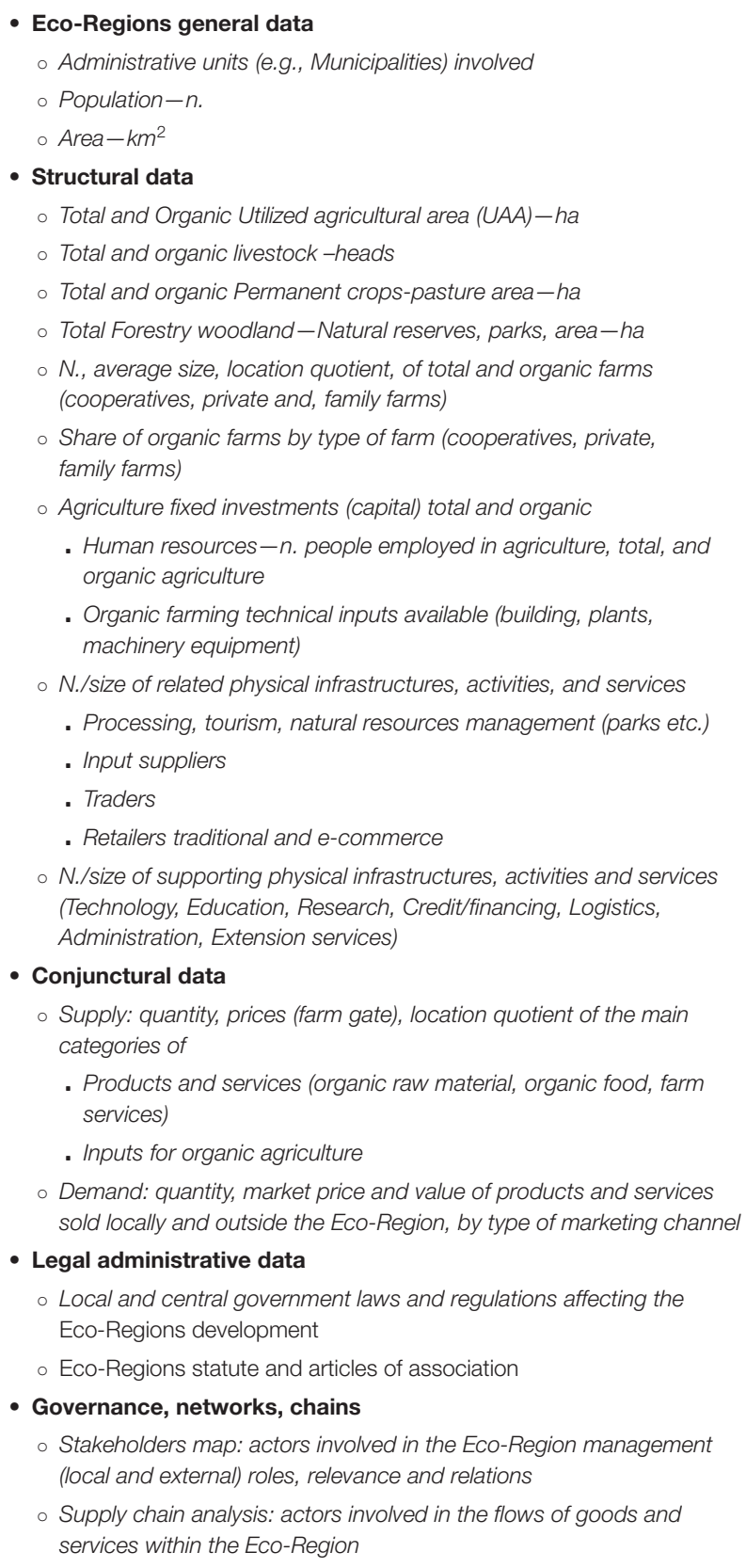

- Supply: quantity, prices (farm gate), location quotient of the main categories of

- Products and services (organic raw material, organic food, farm services)

- Inputs for organic agriculture

- Demand: quantity, market price and value of products and services sold locally and outside the Eco-Region, by type of marketing channel

- Legal administrative data

- Local and central government laws and regulations affecting the Eco-Regions development

- Eco-Regions statute and articles of association

\section{- Governance, networks, chains}

- Stakeholders map: actors involved in the Eco-Region management (local and external) roles, relevance and relations

- Supply chain analysis: actors involved in the flows of goods and services within the Eco-Region

It allows to tailor the development strategies of the EcoRegions to the different roles of the stakeholders and their capacity to influence the Eco-Region dynamics. An example of a stakeholders map related to the Cilento Eco-Region is shown in Figure 3.

A description of the Eco-Regions core supply chains (products and services) shows the level of differentiation and integration of the Eco-Region economic structure and the potential for external economies of scale, due to the presence of a critical mass of activities at the different links of the supply chain. An example 


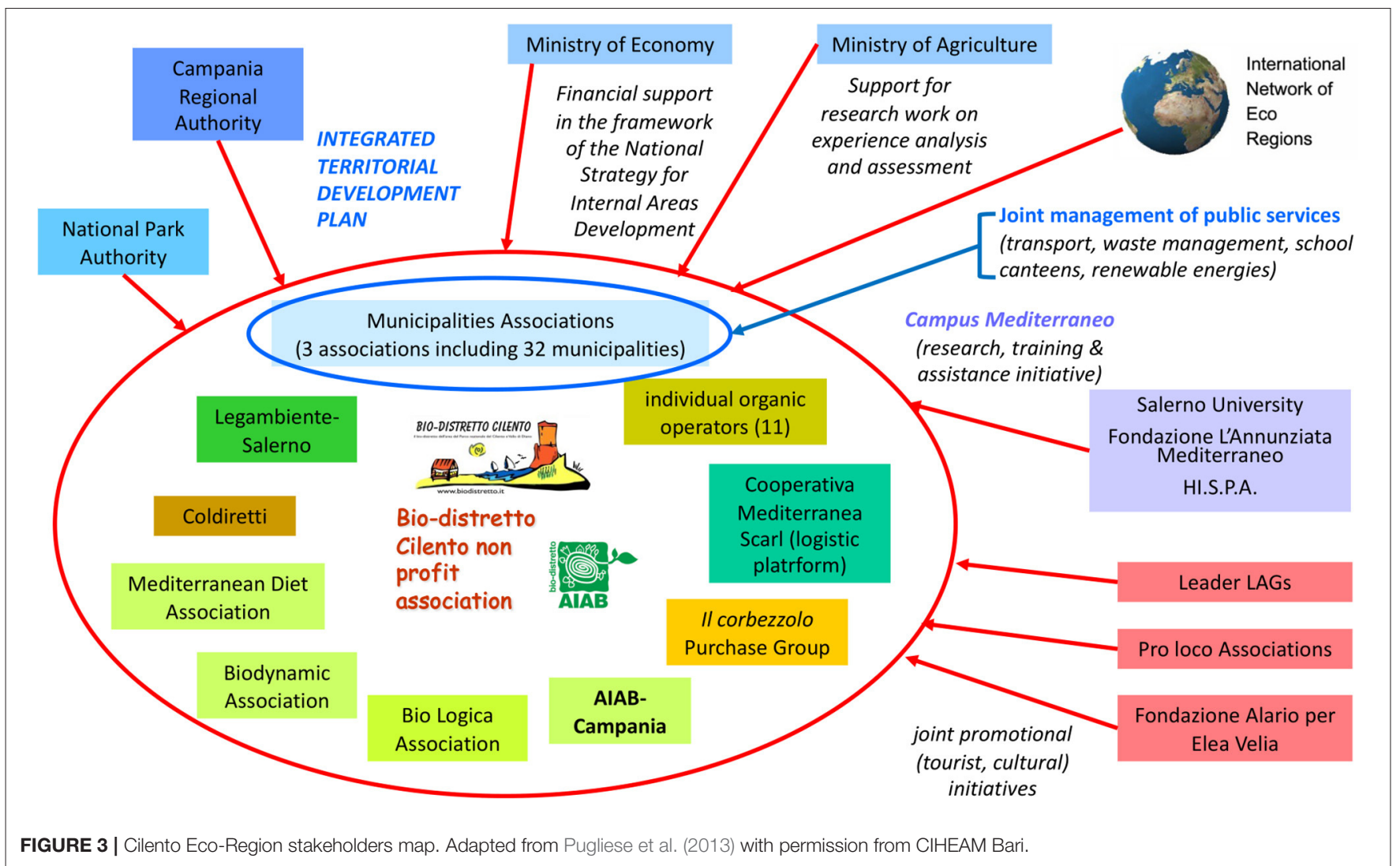

of the supply chain structure of the Cilento Eco-Region is shown in Figure 4.

\section{Context analysis data collection}

Secondary data from quantitative statistics, administrative documents, a questionnaire for structured, semi-structured interviews and unstructured interviews can be adopted. The data collection should be carried out by local agents, which might coincide with the interviewers. They should be selected on the base of their professional skills, covering the different dimensions of the local integrated development (technical, economic, social, and environmental), as well as on their third-party perspective, with respect to the Eco-Region development.

\section{Module 3 Compliance to the Rules, Vision, and Strategic Objectives}

In this module, information gathered from the modules 1 and 2 are compared to the set of overall and specific objectives guiding the different Eco-Regions strategies. Considering the necessity to apply the monitoring tool to different Eco-Regions, possibly adopting different sets of values and principles, the module only provides a general method of assessment. Each Eco-Region will in fact choose the indicators and other information to be collected at the different modules, consistent with their objectives. Structured and semi-structured interviews will therefore include specifically tailored questions, as well as the secondary data variables list. As an example, the following objectives, derived from the
IN.N.E.R. statute, involve the promotion of new direct relations between farmers and consumers, and the communication of the organic farming approach. The valorization of the Terroir and the promotion of food sovereignty and social agriculture are also important objectives of the Eco-Regions. Other objectives strictly related to support a sustainable organic agriculture development are the promotion of Mixed Farming, the simplification of certification and control rules and the promotion of the coexistence between different production techniques (Biodistretto.net).

These objectives, coming from an extensive and influential network of Eco-Regions, can be considered as representative of the Eco-Regions strategic orientation. This module does not relate to performances, as intended in the original Porter's Diamond approach, but answers two relevant questions specific to the characteristics of the Eco-Regions. The first relates to find a flexible way to define an Eco-Region. Instead of the traditional indicators related to the spatial concentration and specialization, the emphasis is here placed on the compliance to a variable set of technical, social and ethical objectives related to the organic movement vision. This mirrors the present stage of development of the Eco-Regions definition, where a standardized set of rules has not yet been defined. The nature of this monitoring tool is in fact not to provide regulations, but to support the different local initiatives aiming at the development of Eco-Regions. The second question this module answers is: "how far is the Eco-Region to fully comply to its strategic objectives?" Together with module 


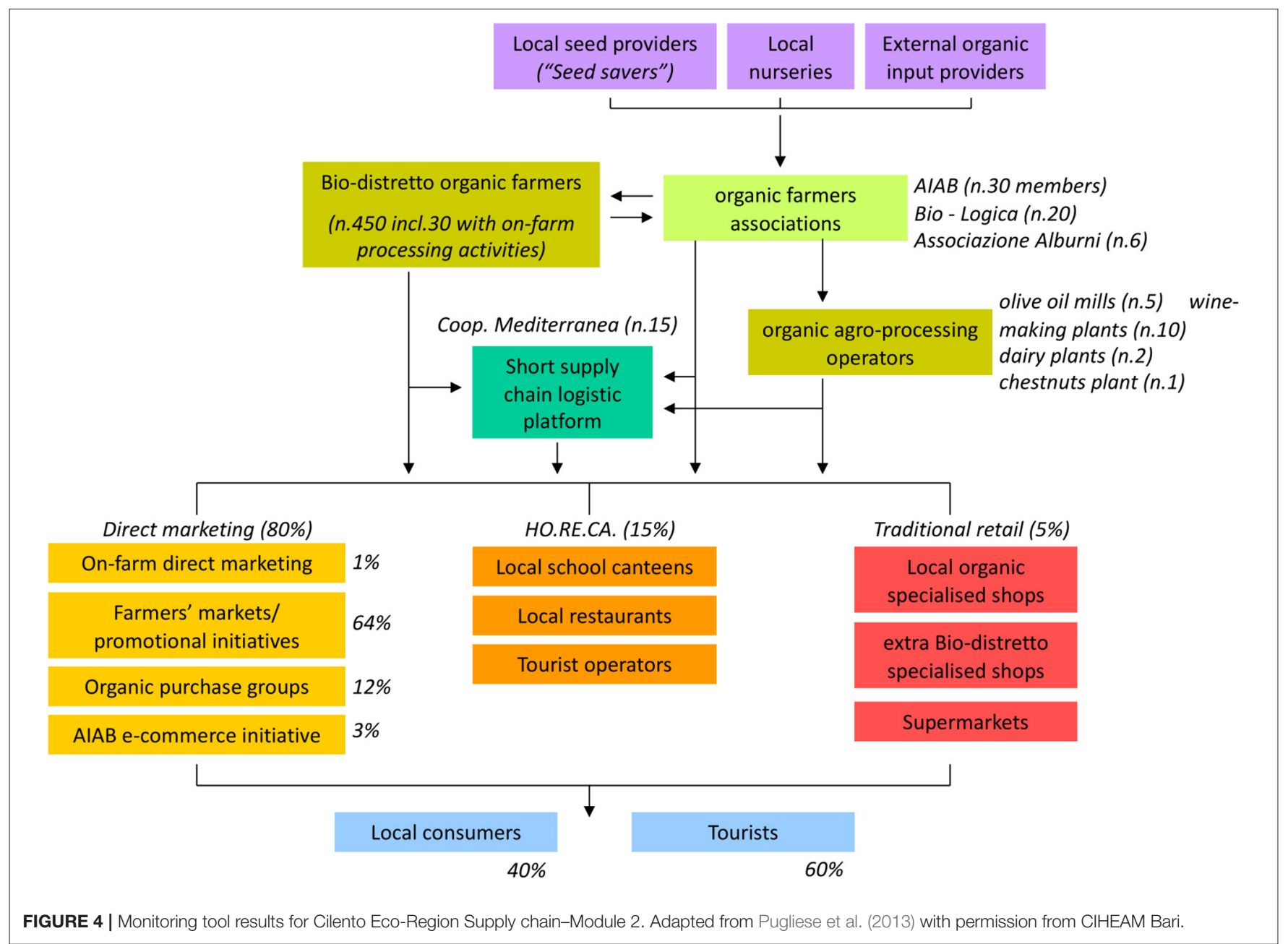

4 a description of the stage of development of the Eco-Region is provided.

Score calculation: a score from 1 to 5 is assigned to each different Eco-Region objectives and values above listed. An average of the different indicators scores, addressing the EcoRegion values and objectives, is calculated to this end. A final adjustment will be provided as a result of a joint interpretation stage, involving the local agents and the expert respondents.

\section{Module 4 Eco-Region Development Stage}

This module aims at assessing the development stage of an Eco-Region as a support to public and private interventions.

The development stages have been classified considering the influence of the different approaches reported in the literature analysis, all rooted in, and coherent with, the Porter's model for clusters analysis. These involve the "four stages of clusters development: antecedence, formation, launch and formal institution" (Solvell et al., 2003); the (i) groundwork clusters, (ii) industrializing clusters, (iii) complex industrial clusters defined in the collective efficiency approach (McCormick, 1999) and the Flexible Specialization framework (Sabel, 1989) where the flexibility and specialization of the workers and of the role of private and public institutions in stimulating the product differentiation and innovation, are considered.

These different aspects are summarized in the characteristics of a fully developed cluster (Porter, 1998; Porter et al., 2004).

The following basic drivers are considered and assessed in terms of their distance from a fully developed cluster, in order to classify the different stages of an Eco -Region development.

The presence within the Eco-Region of a critical mass of core and complementary activities and businesses (farms included) capable of activating synergies among the actors of the cluster (specialization, flexibility, economies of scale, and scope).

The extent of horizontal and vertical relations between operators along the chain involving external economies, joint actions, institutional arrangements.

The diversification, innovations, and typicality of products. Specialization, flexibility, economies of scale and scope, external economies, joint actions, and institutional arrangements are considered.

The presence of marketing channels within and outside the Eco-Region; institutional links between central and local government (institutional arrangements); the change in number and size of local companies; the presence of outsourcing and 
relocation of activities outside the Eco-Region. The obsolescence of the present technologies is also considered and the rigidities in public and private strategies preventing the adaptation to a changing competitive scenario. From the demand side the change in consumers demand and the participation of the Eco-Region population and consumers to its development, are included in the module.

The Context and Structure and performance analysis provide data and information supporting the module implementation.

According to the characteristics of these drivers, the following stages of development have been defined to better tailor the different Eco-Regions contexts: initial, infant, unstructured, takeoff, maturity and decline.

At an initial stage, a critical mass of complementary activities is present and can support the development of relations between the different actors, influencing the development process. The quantity and quality of the relations between the stakeholders is still low. The horizontal and vertical relations between the actors of the Eco-Region chains show a low level of functional integration. The local supply of products and services is limited and only little differentiated. Local resources (capital and labor) are scarce and there is little coordination as regards the activities characterizing the Eco-Region (e.g., organic farming). The relations of the Eco-Region community (local private companies and civil society) with the local and central government are still limited; the range of policy intervention areas is still limited as well as the scope and quality of public investments and regulations. The relations between organic farms (the core of the Eco-Region activity) and the other related activities and services such as credit, training, and research institutions, are still limited. The local population is little aware of the existence and relevance of the Eco-Region, and this reflects also on the demand for local products and services; the role of the consumers in supporting the products and services quality is limited.

In an Eco-Region at the infant stage the size, quality, and variety of factors listed are present but at a much lower level. An even lower stage of development defines the unstructured stage, where the factors driving the Eco-Region initial development (critical mass of activities, quantity and quality of inputs, role of government, and communities) are totally lacking, making it nearly impossible a bottom-up development process. This seems to be the case in some disadvantaged regions, mostly located in the Global South, where a top-down development process could represent the only option for an Eco-Region development.

In the take-off stage, the number of core and related activities in the Eco-Region increases, consolidating their critical mass; the functional relations between the focal activity of the Eco-Region (e.g., organic farming) and the other stakeholders involved in local development, strengthen; in particular the horizontal and vertical relations between the chain agents tighten; innovative, or more complex governance and organizational models start to emerge. A large number of differentiated products and services are supplied at the local level, like specific touristic packages related to the Eco-Region activities, certification bodies, research centers, local credit and government; the level of available local resources (capital and labor) and their quality increase as well. The local communities actively participate in development initiatives related to the Eco-Region, both as producers of goods and services, and as consumers.

In a maturity stage, the potential for economic, social, and environmental development is fully exploited in terms of expansion in the quantity of products and services produced. The still important role played by the Eco-Region actors (public, private, and civil society institutions) supports a further increase of the quality of the goods and services.

In a decline stage, the number and size of activities reduces, outsourcing outside the Eco-Region increases, the local level of functional integration (horizontal and vertical integration) therefore diminishes.

The rate of investments and innovation in products, services, governance and organizational models slows down. The local supply of products and services, and their differentiation and specialization, decreases.

Discontinuity in external environment renders obsolete the market information, the skills, scientific and technical expertise of the employees and of the suppliers base. The demand for the core products and services of the Eco-Region decreases, rigidities in government, education, and research institutions increase. The local population becomes less interested in the initiatives related to the Eco-Region and their role as promoters of local development and active consumers decreases.

Score calculation: the score assessment of the different drivers and of the Eco-Region development stage will follow the same approach as the one related to the compliance to the Eco-Regions values and objectives. Eventually, classes of interval defining the different stages could be set according to the different contexts of a cluster in a joint local stakeholder, LTIT, and MTIT evaluation.

\section{Module 5 Eco-Region Market Orientation}

The market orientation is particularly significant to define sustainable and coherent strategies of development for an EcoRegion, given its "influence [on] the regional performances and its causes” (Porter et al., 2004).

Market orientation influences the whole Eco-Region business model: farming, processing and distribution of organic products, including the local production structures and the infrastructures. Social aspects like food sovereignty, the relations within and outside the Eco-Region, environmental aspects related to the tourism development model and consequent impact of new residential areas, are also affected.

Nine different market orientation strategies have been identified, based on a comparison between the present and the potentially more efficient market orientation (see Table 3 ), providing a first indication on the development strategy to be followed by an Eco-Region.

According to the logic of the three types of market orientation, as defined by Porter et al. (2004), and their specific adaptation to the characteristics of each Eco-Region (Pugliese et al., 2013), the prevailing destination of goods and services by type of consumers or marketing channel, defines different Eco-Regions market orientations.

In Inward-looking Eco-Regions, the local consumption from resident population prevails; a different type of Inward-looking market orientation is one based on the consumption from 
TABLE 3 | Present and Potential market orientation strategy.

Variables defining the type of market orientation

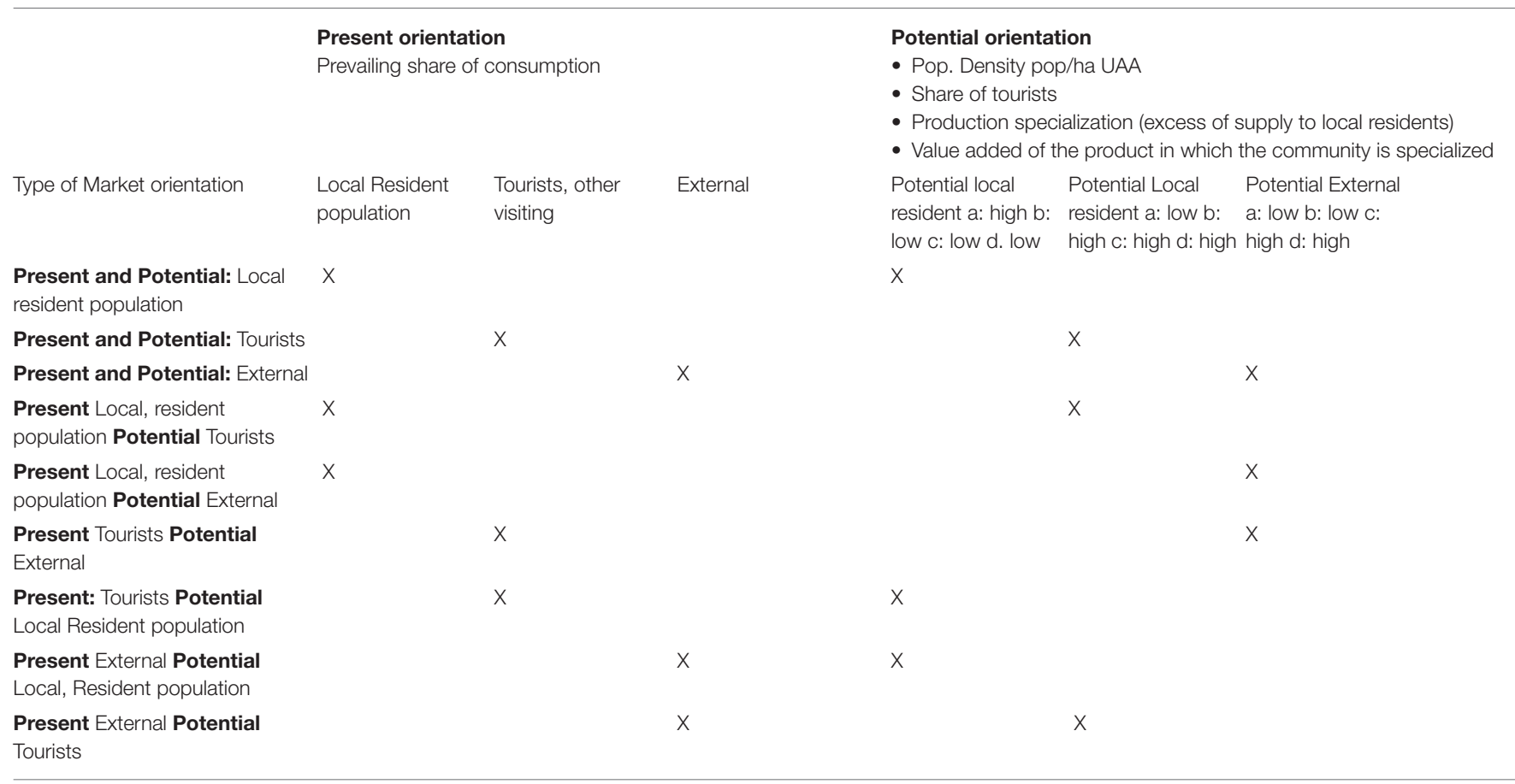

Adapted from Pugliese et al. (2013) with permission from CIHEAM Bari.

tourists; a third market orientation type is defined as Export led where most of the food is consumed outside the Eco-Region.

The potential, most efficient market orientation is assessed from a combination of the following indicators.

Local population density (a): is an indicator of the potential for local demand to absorb the supply. It is measured in terms of pop/ha of UAA (utilized agricultural area). This could influence the contribution of organic products and services to the local food security, safety and food sovereignty.

Ratio of tourists to the local population (b): it is and indicator of the Eco-Region potential for developing a tourist-oriented market strategy.

Product specialization (c): the more an Eco-Region is specialized in few products or services the more they are potentially oriented toward external trade. The revenues provided by its export-oriented activities could eventually support a locally based supply and demand development, positively influencing the local economy differentiation.

Added value of the product (d): a differentiated, high valueadded organic products and services can be more easily sold to tourists or exported. This is assessed by integrating data from module 1 and 2 .

The variables combination defining the type of potential market orientation, available from the Context and the Structure and performance analysis, are reported in Table 3.

An overview of aggregated results from modules 1, 3, 4, and 5, from the previous application of the Monitoring tool to the Cilento Eco-Region (Pugliese et al., 2013) are reported in Figure 5.

\section{Development Strategies Suggestions}

The module aim is to support the public and private stakeholders in designing the development strategies of an Eco-Region.

Porter defined a framework listing the main role a government, the private sector and associations could play (par.3.1.2.3 and Figures 1A,B). Within this framework the results of the monitoring tool modules should be integrated to adjust and fine tune an Eco-Region development strategy. At first a list of actions should be defined to improve the Eco-Region capacity to fulfill its objectives and comply to the rules defining their identity, starting from the results of the Compliance to the rules vision and strategic objectives module. These actions need to be harmonized to the context of the EcoRegion, described in the Development stage module and the Market orientation module. The Eco-Region competitive location advantages module provides the necessary information to fine tune the policies defining the specific areas of intervention. As an example, if an Eco-Region needs to improve its food sovereignty the market orientation module will define how relevant this objective is, in terms of supporting the overall Eco-Region development, given the present development stage. In case an Eco-Region is at an infant stage of development, is potentially oriented toward attracting tourists, and resources are needed to implement the communication infrastructures conditions, food sovereignty could not be considered a shortterm priority. In a long-term strategic plan, the Eco-Region should implement policies to support food sovereignty once enough resources are made available from the touristic sector. These are just examples of how to use the Eco- Region 


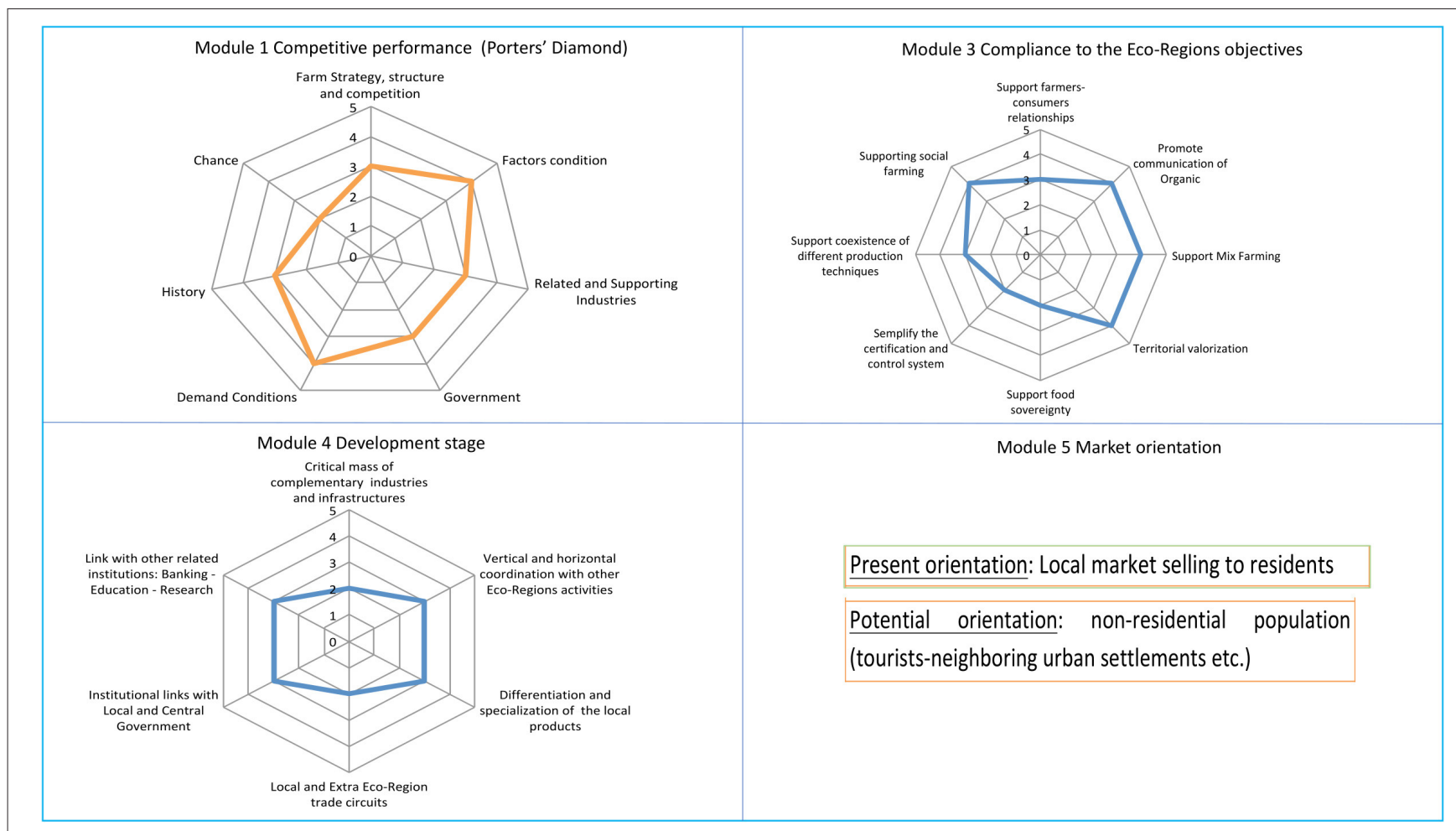

FIGURE 5 | Result of the Monitoring tool application to the Cilento Eco-Region. Adapted from Pugliese et al. (2013) with permission from CIHEAM Bari.

monitoring tool results. The definition of specific policies will be supported by a joint discussion with the Eco-Region representatives, based on the Monitoring tool results (see Figure 6).

Furthermore, an effective knowledge exchange between EcoRegions will be supported. First of all, a clearly defined and broad range of information on the Eco-Regions structure, organization and management, requested to implement the performance monitoring, can be shared with other Eco-Regions; the different strategies applied to improve the Eco-Regions performances, consequent to the monitoring results, and the successive analysis of the improvement strategies impact on the EcoRegion development, can be also made available. The possibility to create a web-based platform where the different EcoRegions can exchange their information, and the organization of conferences, seminar and other events, will provide the EcoRegions representatives the chance to share their information and eventually adapt the other Eco-Regions experiences to their contexts.

\section{DISCUSSION}

\section{Key Findings of the Study}

From the literature analysis a list of the requirements for designing an effective and efficient clusters performance monitoring tool has been defined and checked against the features of the Eco-Regions monitoring tool. The comparison shows a limited breadth and depth in the analytical framework previously adopted, based on the Porter's Diamond model. An incomplete definition of the indicators categories and of their role in the Eco-Regions development resulted. As a consequence, changes were made in the present manuscript by broadening the scope of the analysis and adding many new indicators (see Table 1 and Supplementary Tables 3A-F). In particular, considering the Firm Strategy, Structure and Cooperation determinant, the Eco-Region climate for investments has been more specifically detailed by adding macro and microeconomic indicators (e.g., income pro-capita; unemployment, level of salaries, interest rate) as well as social indicators (e.g., political and social stability, food safety, sovereignty and security, level of corruption, etc.). Indicators of local policies affecting rivalry as well as indicators of cooperation and competition have been redesigned according to better fit the Porter description. The Diamond determinant Factor (input) condition has also been more clearly tailored to the Eco-Region features by adding environmental sustainability indicators; innovation indicators and more detailed indicators of human resources conditions have also been added (e.g., the human resources inflows and outflows influence on labor availability, child labor, and gender gap for labor quality). As far as the Related manufacturing and services structures and infrastructures are concerned, the role of tourism is more extensively analyzed. New more detailed categories have been added to the Related industries and services Determinant: technologies, scientific and technologic infrastructures, digital infrastructures, logistic, and administrative infrastructures. The 


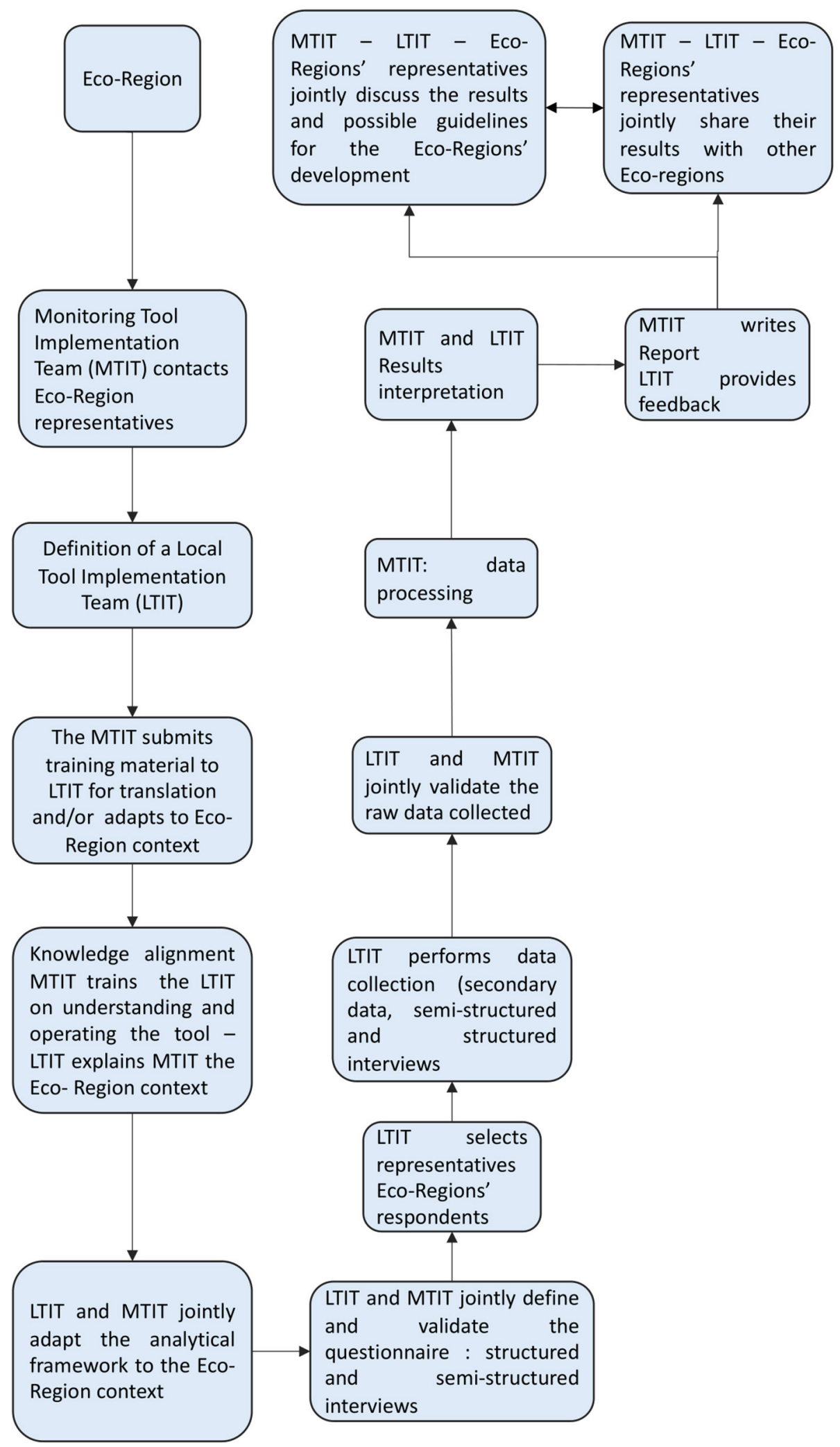

FIGURE 6 | Eco-Regions' implementation activity action map. 
related activities have been separated from the supporting activities to more clearly analyze the direct and indirect locative advantage factors in each Eco-Region. The Demand Condition indicators increased the depth of the analysis distinguishing the local demand from the role of the tourists and export led demand in influencing the Eco-Region locative advantage. The Government role has been completely redesigned to more clearly mirror the Porter's framework and increasing the overall consistency of the theoretical construct. The categories Government role in Improvement of general micro-economic capacity of the economy and Formal Agreements and formal and informal collaborations private/public/civil society have been added defining a clearer logical framework for the detailed specification of the indicators.

The same consideration applies to the History/Chance Determinant. A substantial reorganization of the categories of indicators related to History and Chance has been carried out, where the contribution of previously existing favorable location factors (History) and of chance events influencing the Eco-Region development are listed in detail.

Other modules included in the monitoring tool have also been improved: the assessment of the Compliance to the EcoRegions objectives and values, the Development stage assessment and the Market present orientation compliance to the EcoRegion potentially more efficient market orientation. The most relevant improvements in these modules relate to the explicit inclusion of food sovereignty in the analysis, allowing for a more detailed evaluation of the Eco-Regions compliance to their objectives; another important aspect relates to the EcoRegion development stage module, where the new indicators allow for a clear definition of a possible decline stage, which has been added to the theoretical framework describing the Eco-Region development.

The Market orientation module has been integrated with added information on its contribution to the definition of the development strategies of Eco-Regions.

The improvements made to the monitoring tool design not only benefit the analysis of the Eco-Regions but can be more effectively applied to other areas where sustainable food systems development strategies should be implemented through a bottom-up process. The Porter's clusters analysis proved to be an effective approach to this end.

\section{The Boundaries of the Monitoring Tool Application}

The monitoring of Eco-Regions is based on information resulting from a mixed qualitative and quantitative analysis, strongly influenced by the opinion of local stakeholders and experts. The degree of subjectivity makes the tool very useful as a knowledge base for designing the directions of an Eco-Region development policy and its impact, based on a clearly and organically defined set of influencing factors. It does not provide quantitative thresholds or other pre-defined criteria for selecting or classifying the Eco-Regions. Considering the different EcoRegions regulatory contexts, the results of the Eco-Region analysis should be checked against the locally defined objectives and selection criteria. Given the different relevance of the indicators in diverse Eco-Regions, a detailed comparison of their performances is not possible, nor recommended, since it encourages competition and imitation instead of focusing on valorizing the differences. Valorizing the Eco-Regions distinctive characters, avoiding the convergence toward a unified goodfor- all model is a way to grant their resilience and to support bottom-up initiatives and innovations. The present analytical framework defines a common language and a shared analytical framework which will support the knowledge exchange between Eco-Regions, further contributing to the valorization of their specific characteristics.

\section{Shortcomings and Further Research Directions}

One of the main shortcomings of this study concerns the difficulty of translating the Porter's Diamond model theoretical construct in a clearly structured set of hypotheses defining a consistent and exhaustive analytical framework. The risk of overlapping indicators placed in different Diamond Determinants and the difficulty to exactly define their role in the development of an Eco-Region is consistent. This makes it difficult to design the monitoring tool and interpret the results. These difficulties are likely to increase with the number of indicators adopted and the complexity of the cluster structure.

Further research directions should delve into the Porter's Diamond description and possibly define a more detailed and structured model where the description of different Determinants, the choice of indicators, and their relations, can be more explicitly described. A more organized and consistent package of decision support tools can result, improving the efficiency and effectiveness of the management of Eco-Regions. This will also improve the effectiveness of the multi-stakeholders approach. A lengthy and complex explanation of the tool framework can negatively affect the trust and collaborative atmosphere between the implementation teams and the local stakeholders, necessary to the analysis implementation. The choice of training a Local Tool Implementation Team is consequent to the necessity to reduce the cultural distance between the local stakeholders and the Monitoring Tool Implementation Team characterized by specialists possibly not belonging to the Eco-Regions context. Further research should address an analysis of the factors influencing trust and collaboration among the different actors involved in the EcoRegion monitoring tool design and implementation, in different contexts. Linking and harmonizing the Eco-Regions monitoring tool with other Eco-Region management support tools (e.g., multicriteria decision tools, business plan, cost/benefit analysis) could also be of interest for further studies.

\section{AUTHOR CONTRIBUTIONS}

All authors contributed to the conception, design of the study, and to the questionnaire list of indicators. $\mathrm{CZ}, \mathrm{SB}$, and $\mathrm{PP}$ wrote the introduction. Individual contributions: $\mathrm{CZ}$ wrote the first draft of the manuscript, wrote the materials and 
method, contributed to the literature analysis structure and in particular followed the definition of the monitoring tool improvement needs and their integration into an improved analytical framework, contributed to the analytical framework and to the modules on Eco-Regions development stages and market orientation, and wrote the Discussion. SB contributed to the literature review in particular wrote the parts on clusters in developing countries, Tourism and Rural clusters, and contributed to the analytical framework and monitoring tool design in particular the Compliance to the Eco-Regions objectives module. FP contributed to the literature analysis, in particular wrote the parts on clusters sustainability food safety security and sovereignty, and to the development stages literature analysis. PP contributed to the literature analysis in particular the Eco-Regions and Rural Clusters Definition and identification, also wrote the part on cluster policies, and contributed to the analytical framework and monitoring tool design in particular the module of Eco-Regions context analysis. CR contributed to the literature analysis on the factors influencing the clusters

\section{REFERENCES}

Abdallah, R., Barry, C., Beal, M., Said, A., and Vartanov, S. (2012). The Textile Cluster in Egypt. Institute For Strategy \& Competitiveness.

African Union Commission (2018). Post-Harvest Loss Management Strategy. Addis Ababa.

Agrawal, A., Brown, D. G., Rao, G., Riolo, R., Robinson, D. T., and Bommarito, M. (2013). Interactions between organizations and networks in common-pool resource governance. Environ. Sci. Policy 25, 138-146. doi: 10.1016/j.envsci.2012.08.004

AIAB (2017). Nasce ufficialmente la Rete Nazionale dei Biodistretti AIAB. Available online at: https://aiab.it/nasce-ufficialmente-la-rete-nazionale-deibiodistretti-aiab-lunico-marchio-garantisce-la-valorizzazione-dal-basso/ (accessed February 8, 2020).

Andersson, T., Hansson, E., Schwaag Serger, S., and Sörvick, J. (2004). The Cluster Policies Whitebook. Malmo: IKED.

Babalola, A., Bennis, K., Caltigirone, M., Manjarreaz, J. L., and Tanizawa, A. (2011). Tourism Cluster in Italy Microeconomics of Competitiveness Final Report. Institute For Strategy \& Competitiveness.

Bakan, I., and Dogan, I. (2012). Competitiveness of the industries based on the Porter's diamond model: an empirical study. Int. J. Res. Rev. Appl. Sci. $11,441-455$.

Basile, S. (2019). "Presentation: scaling up agroecology to achieve the sustainable development goal," in Proceedings of the Second FAO International Symposium (Rome).

Becattini, G. (1987). Mercato e forze locali: il distretto industriale. Il mulino.

Becattini, G. (1989). Modelli locali di sviluppo. Il mulino.

Belai, A., and Boakye, D. (2011). The Malaysian Palm Oil Cluster Final Report. Institute For Strategy \& Competitiveness.

Biodistretto.net (2020). BIO-DISTRETTO - Portale dei Bio-distretti (or EcoRegions). Available online at: https://biodistretto.net/ (accessed February 8, 2020).

Boja, C. (2011). Clusters models, factors and characteristics. Int. J. Econ. Pract. Theor. 1:10.

Bruni, L., and Zamagni, S. (2016). Civil Economy: Another Idea of the Market. Available online at: http://www.jstor.org/stable/10.2307/j.ctv5cg8w2 (accessed February 18, 2020).

Carpinetti, L. C. R., Galdámez, E. V. C., and Gerolamo, M. C. (2008). A measurement system for managing performance of industrial clusters: a conceptual model and research cases. Int. J. Product. Perform. Manag. 57, 405-419. doi: 10.1108/1741040081088 1854 development dynamics and on the Porter's application to generic clusters, contributed to the monitoring tool design where wrote the parts on Rural clusters, the questionnaire validation, and data collection and the performance score. All authors contributed to the manuscript revision, read, and approved the submitted version.

\section{ACKNOWLEDGMENTS}

The authors wish to thank the Cilento Bio-district Association for sharing their information and experience, supporting the definition of the monitoring tool analytical framework.

\section{SUPPLEMENTARY MATERIAL}

The Supplementary Material for this article can be found online at: https://www.frontiersin.org/articles/10.3389/fsufs. 2020.536392/full\#supplementary-material

Center for Strategy and Competitiveness (2020). Center for Strategy and Competitiveness Clusterobservatory. Available online at: http://www. clusterobservatory.eu/ (accessed February 11, 2020).

Crivits, M., de Krom, M. P. M., Dessein, J., and Block, T. (2018). Discursive representation within the institutional void: the rise and fall of a governance network on sustainable food in Belgium. Sociol. Ruralis 58, 475-499. doi: $10.1111 /$ soru. 12162

Decreto 18 Maggio (2001). Gazzetta Ufficiale della Repubblica Italiana.

Decreto 22 luglio (2019). Gazzetta Ufficiale della Repubblica Italiana.

Dorzhieva, E. V., and Dugina, E. L. (2015). The formation of agro-food clusters as a competitiveness growth factor. Int. J. Econ. Financ. Issues 5, 238-247.

European Conference on Rural Development, C. (2016). Cork 2.0 Declaration 2016.

Feser, E. J., and Luger, M. I. (2003). Cluster analysis as a mode of inquiry: its use in science and technology policymaking in North Carolina. Eur. Plan. Stud. 11, 11-24. doi: 10.1080/09654310303664

Food and Agriculture Organization (2019). United Nations Decade of Family Farming.

Food and Agriculture Organization (FAO). (2013). Sustainability Assessment of Food and Agriculture Systems. Guidelines Version 3. 0. Available online at: http://www.fao.org/nr/sustainability/sustainability-assessments-safa/en/ (accessed February 12, 2020).

Gálvaez, E. (2010). Agro-Based Clusters in Developing Countries: Staying Competitive in a Globalized Economy FAO. Available online at: http://www.fao. org/3/i1560e/i1560e.pdf (accessed February 8, 2020).

Gordillo, G. (2013). Food Security and Sovereignty, (base document for discussion). Available online at: http://www.fao.org/3/a-ax736e.pdf (accessed June 17, 2020).

Gunther Egi, M. (2014). The Dynamics of the Norwegian Maritime Industry. Lund Sweden.

Gustafson, D., Gutman, A., Leet, W., Drewnowski, A., Fanzo, J., and Ingram, J. (2016). Seven food system metrics of sustainable nutrition security. Sustainability 8:196. doi: 10.3390/su8030196

Harvard Business School (2019). Institute for Strategy and Competitiveness. ISC. Available online at: https://www.isc.hbs.edu/about-the-institute/Pages/default. aspx (accessed February 11, 2020).

HealthyGrowth (2017). Case Study and Fact Sheets.

Hudson, M., Smart, A., and Bourne, M. (2001), Theory and practice in SME performance measurement system. Int. J. Oper. Prod. Manag. 21, 1096-1115.

Ketels, C. H. M. (2013). Clusters and Public Policy : Recent Learnings, Current Challenges. Wrocław: Wrocław University of Economics. 
Knickel, K., Redman, M., Darnhofer, I., Ashkenazy, A., Calvão Chebach, T., Šumane, S., et al. (2018). Between aspirations and reality: making farming, food systems and rural areas more resilient, sustainable and equitable. J. Rural Stud. 59, 197-210. doi: 10.1016/j.jrurstud.2017.04.012

Lamine, C. (2015). Sustainability and resilience in agrifood systems: reconnecting agriculture, food and the environment. Sociol. Ruralis 55, 41-61. doi: 10.1111/soru.12061

Lee, A. H. J., Wall, G., Kovacs, J. F., and Young Kang, S. (2016). Food clusters and creative tourism development: a conceptual framework. J. Rural Community Dev. $11,72-88$.

Legge 27 dicembre n. 205, 2017 (2017). Gazzetta Ufficiale della Repubblica Italiana.

Lindqvist, G., Ketels, C., and Sölvell, O. (2013). The Cluster Initiative Greenbook 2.0. Stockholm: Ivory Tower Publishers.

Malorgio, G., Mulazzani, L., Pugliese, P., Rota, C., Zanasi, C., and Zuccaro, M. (2017). The role of small-scale fisheries in Mediterranean coastal communities. An analytical framework for their development. New Medit 16, 19-26.

Marshall, A. (2013). Principles of Economics. New York, NY: Springer. doi: $10.1057 / 9781137375261$

McCormick, D. (1999). African enterprise clusters and industrialization: theory and reality. World Dev. 27, 1531-1551. doi: 10.1016/S0305-750X(99)00074-1

Mondy, B., Terrieux, A., Gafsi, M., and Hemptinne, J. L. (2009). Enjeux et perspectives de développement de l'Agriculture Biologique en Midi-Pyrénées. Innov. Agron. 4, 337-388.

Muro, M., and Katz, B. (2011). The new "cluster moment": how regional innovation clusters can foster the next economy. Adv. Study Entrep. Innov. Econ. Growth 22, 93-140. doi: 10.1108/S1048-4736(2011)0000022008

Neven, D., and Dröge, C. L. M. (2000). “A diamond for the poor?” in Assessing Porter's Diamond Model for the Analysis of Agro-Food Clusters in the Developing Countries (East Lansing, MI), 13.

Nolan, C., Cordes, S., Waldorf, B., Conover, J., Rogers, C., Kumar, I., et al. (2007). Unlocking Rural Competitiveness: The Role of Regional Clusters. Purdue, IN: Indiana Business Research Center.

Noronha Vaz, T., and Gomes, J. (2013). Innovation for Sustainability and Networking. Faro: Universidade do Algarve.

Odu, G. (2019). Weighting methods for multi-criteria decision making technique. J. Appl. Sci. Environ. Manage. 23:1449. doi: 10.4314/jasem.v23i8.7

Pancino, P., Franco, S., and Marino, D. (2013). "Identificazione dei 'Distretti Biologici': un approccio metodologico," in Quaderno di Progetto Per Un Futuro Sostenibile Della Tiberina Coesione territoriale e sviluppo endogeno fra tradizione e innovazione, ed E. P. U. Srl (Terni), 37-40.

Pinto, J. (2011). Right to Food and Food and Nutrition Security in the CPLP Countries, FAO, Assessment Report. Available online at: http://www.fao.org/ right-to-food/resources/resources-detail/en/c/179565/ (accessed February 8, 2020).

Porter, M. (1990). Competitive advantage of nations. Compet. Intell. Rev. 1:14. doi: 10.1002/cir.3880010112

Porter, M., and Ketels, C. (2009). "Clusters and industrial districts: common roots, different perspectives," in A Handbook of Industrial Districts, eds G. Beccattini, M. Bellandi, and L. De Propis (Cheltenham, UK: Edwad Elgar Publishing), 172-186. doi: 10.4337/9781781007808.00024

Porter, M., Takeuchi, H., Baibakova, M., Guilford, M., Lee, J., Sarafa, R., et al. (2013). The French Wine Cluster Microeconomics of Competitiveness. London: Palgrave Macmillan.

Porter, M. E. (1998). "Clusters and competition: new agendas for companies, governments and institutions," Harvard Business School Working Paper (Cambridge, MA).

Porter, M. E. (2008). "Clusters, innovation, and competitiveness : new findings and implications for policy," in European Presidency Conference on Innovation and Clusters (Stockholm).

Porter, M. E., Ketels, C. H. M., Miller, K., and Bryden, R. T. (2004). Competitiveness in Rural US Regions: Learning and Research Agenda. Policy 1-70. Available at: http://www.isc.hbs.edu/pdf/EDA_RuralReport_20040621. pdf (accessed January 7, 2020).

Pugliese, P., Antonelli, A., and Basile, S. (2015). Bio-Distretto Cilento - Italy: Full Case Study Report. Bari: CIHEAM Bari and Aarhus: HealthyGrowth. Available online at: http://orgprints.org/29252/7/29252.pdf
Pugliese, P., Antonelli, A., Rota, C., Zanasi, C., and Basile, S. (2013). L'agricoltura Biologica In Chiave Territoriale - L'esperienza Dei Bio-Distretti in Italia. Bari: CIHEAM.

Ramirez, M., Bernal, P., Clarke, I., and Hernandez, I. (2018). The role of social networks in the inclusion of small-scale producers in agri-food developing clusters. Food Policy 77, 59-70. doi: 10.1016/j.foodpol.2018.04.005

Remans, R., Wood, S. A., Saha, N., Anderman, T. L., and deFries, R. S. (2014). Measuring nutritional diversity of national food supplies. Glob. Food Sec. 3, 174-182. doi: 10.1016/j.gfs.2014.07.001

Sabel, C. (1989). "Flexible specialization and the reemergence of regional economies," in Reversing Industries Decline, eds P. Hirst and J. Zeitlin (New York, NY: St. Martin's Press), 17-70.

Schermer, M. (2006) "Regional rural development: formation of ecoregions in Austria," in Sociological Perspectives of Organic Agriculture: From Pioneer to Policy, eds G. Holt and M. Reed (Wallingford: CABI Publishing), 227-242.

Serrat, O. (2017). “The five whys technique," in Knowledge Solutions (Singapore: Springer), 307-310. doi: 10.1007/978-981-10-0983-9_32

Sheppard, E. (2000). "Competition in space and between places" in A companion to Economic Geography, eds E. Sheppard and T. J. Barnes (Oxford: Blackwell Publishing Ltd), 169. doi: 10.1002/978047069344 5.ch11

Simboli, A., Taddeo, R., and Morgante, A. (2015). The potential of industrial ecology in agri-food clusters (AFCs): a case study based on valorisation of auxiliary materials. Ecol. Econ. 111, 65-75. doi: 10.1016/j.ecolecon.2015. 01.005

Solvell, O., Lindqvist, G., and Ketels, S. (2003). The Cluster Initiative Green Book. Available online at: www.cluster-research.org (acessed January 7, 2020).

Stejskal, J. (2009). Competitiveness Advantage Analysis as One Method for Cluster Identification in Regions. Košice: CERS.

Stotten, R., Bui, S., Pugliese, P., Schermer, M., and Lamine, C. (2017). Organic values-based supply chains as a tool for territorial development: a comparative analysis of three European organic regions. Int. J. Sociol. Agric. Food 24, 135-154.

Sturla, A., Giuca, S., Vaccaro, A., and Rcciardi, G. (2017). Il contributo dell'agricoltura biologica per lo sviluppo sostenibile delle aree rurali. Roma: MIPAAF.

Székely, V. (2014). From enthusiasm to scepticism: tourism cluster initiatives and rural development in Slovakia. Stud. Agric. Econ. 116, 74-81. doi: $10.7896 /$ j.1409

Tamara, K. (2018). RURAL 3.0. Policy Note a Framework for Rural Development. New York, NY.

UN (2019). Sustainable Development Goals: Sustainable Development Knowledge Platform. sustainabledevelopment.un.org, 1. Available online at: https:// sustainabledevelopment.un.org/?menu=1300 (accessed February 8, 2020).

Uyarra, E., Ramlogan, R., and Uyarra, R. (2012). Cluster Policy: A Review of the Evidence. Available online at: http://research.mbs.ac.uk/innovation/ (accessed January 7, 2020).

WNBR (2020). United nations educational, scientific and cultural organization. Int. Organ. 4, 326-327. doi: 10.1017/S002081830002 9234

Yu, M., Calzadilla, J., Lopez, J. L., and Villa, A. (2013). Engineering agrofood development: the cluster model in China. Agric. Sci. 4, 33-39. doi: $10.4236 /$ as.2013.49B006

Conflict of Interest: The authors declare that the research was conducted in the absence of any commercial or financial relationships that could be construed as a potential conflict of interest.

Copyright (C) 2020 Zanasi, Basile, Paoletti, Pugliese and Rota. This is an open-access article distributed under the terms of the Creative Commons Attribution License (CC $B Y)$. The use, distribution or reproduction in other forums is permitted, provided the original author(s) and the copyright owner(s) are credited and that the original publication in this journal is cited, in accordance with accepted academic practice. No use, distribution or reproduction is permitted which does not comply with these terms. 